\title{
Double Differential Cross-Sections for Electron Impact Ionization of Atoms and Molecules
}

\author{
Mevlut Dogan, Melike Ulu, Zehra Nur Ozer, Murat Yavuz, and Gulin Bozkurt \\ Department of Physics, e-COL Laboratory, Afyon Kocatepe University, 03200 Afyonkarahisar, Turkey \\ Correspondence should be addressed to Mevlut Dogan; mevlutdogan@hotmail.com
}

Received 31 May 2013; Revised 17 August 2013; Accepted 2 September 2013

Academic Editor: R. P. S. Chakradhar

Copyright (C) 2013 Mevlut Dogan et al. This is an open access article distributed under the Creative Commons Attribution License, which permits unrestricted use, distribution, and reproduction in any medium, provided the original work is properly cited.

\begin{abstract}
The single ionizing collision between an incident electron and an atom/molecule ends up two kinds of outgoing electrons called scattered and ejected electrons. As features of electron impact ionization, these two types of electrons are indistinguishable. Double differential cross-sections (DDCS) can be obtained by measuring the energy and angular distributions of one of the two outgoing electrons with an electron analyzer. We used $\mathrm{He}, \mathrm{Ar}, \mathrm{H}_{2}$, and $\mathrm{CH}_{4}$ targets in order to understand the ionization mechanisms of atomic and molecular systems. We measured differential cross-sections (DCS) and double differential cross-sections at $250 \mathrm{eV}$ electron impact energy. The elastic DCSs were measured for $\mathrm{He}, \mathrm{Ar}, \mathrm{H}_{2}$, and $\mathrm{CH}_{4}$, whereas the inelastic DCSs of He were obtained for $2^{1} \mathrm{P}$ excitation level for $200 \mathrm{eV}$ impact electron energy.
\end{abstract}

\section{Introduction}

Generally, atomic and molecular physics lead to discoveries about the structure of matter at the atomic or molecular level and explain natural laws. These goals can be achieved with collision methods. Applications of the results from collision physics are of most importance to atmospheric science, laser refinement, and meteorological phenomena. In recent years, an intensive effort of experimental and theoretical work has been devoted to the study of ionization differential cross-sections of atoms and molecules through electron impact. The ionization of rare gas atoms, particularly, the cross-sections obtained with ground state ionization, is considered as benchmark data. Doubly differential crosssections (DDCS) of ionization, as a function of ejected energy, $E_{b}$, and the angle of the ionized electron, $\theta_{b}$, contain valuable information about both the collision dynamics and the internal structure of atomic or molecular systems.

This paper is divided into four main parts. First, the theoretical and experimental studies of elastic DCS and DDCS for Helium, Argon, and Hydrogen molecules and Methane molecules are reviewed. Second, the experimental apparatus and signal processing are described in detail. Then, the results of the elastic DCS and DDCS measurements for $\mathrm{He}, \mathrm{Ar}, \mathrm{H}_{2}$, and $\mathrm{CH}_{4}$ at $200 \mathrm{eV}$ electron impact energy are presented and discussed. Finally, general conclusions are drawn from the experimental results.

\section{Review}

Absolute elastic differential cross-sections for electron scattering from helium were measured for electron energies from 100 to $200 \mathrm{eV}$ by Kurepa and Vuskovic [1], from threshold to $400 \mathrm{eV}$ by Shyn [2], and from threshold to $200 \mathrm{eV}$ by Trajmar et al. [3] and Fon et al. [4]. Normalized DCS below $100 \mathrm{eV}$ have been measured by several authors [5-10]. Also, DCS calculations have been made using various improved methods [11-22].

The DDCS of helium was calculated at high energies in the framework of eikonal approximation $[23,24]$ and in the framework of a distorted wave approximation (DWBA) [25, 26]. The literature contains several results from numerous experimental data of DDCS at intermediate electron energies [27-33].

DCS spectra of Ar provide a test for the comparison of experimental and theoretical data, since a critical minimum appears in the spectra, depending both on the incident electron energy and the scattering angle. Understanding 


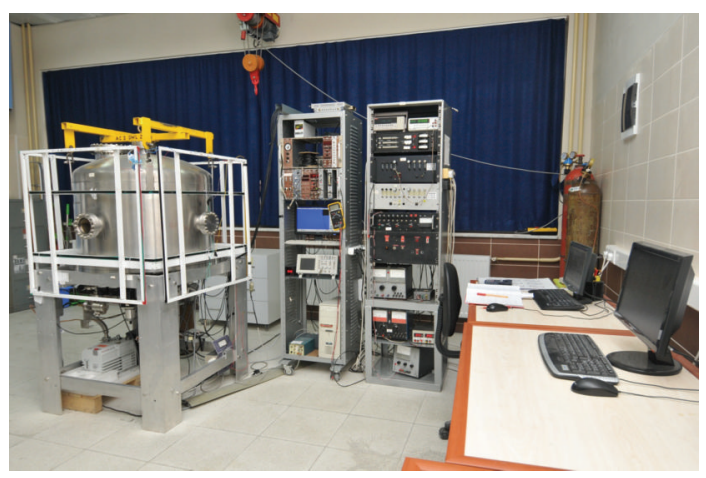

FIgURE 1: The vacuum chamber with Helmholtz coils, target gas containers, electric and electronic control boxes, and the PC of the experimental apparatus at e-COL Laboratory.

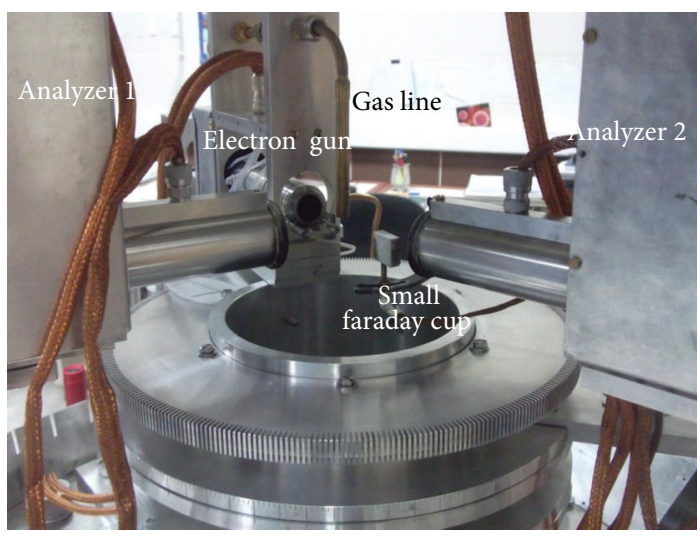

FIGURE 2: A photograph of the electron spectrometer showing the electron gun, the hemispherical analyzers, the Faraday cup, and the gas line. The electron spectrometer is located in the vacuum chamber.

the behavior of this critical point has been the interest of studies of DCSs as a function of the scattering angle [34-39]. The literature contains results from several measurements of the DDCS of Ar at intermediate, high [30, 35, 40-42], and low energies [43].

Molecular hydrogen is the most fundamental of all electron-diatomic molecule scattering systems and has been the subject of numerous experimental and theoretical studies of collision physics. For the first time in the literature, the elastic scattering of electrons by $\mathrm{H}_{2}$ was measured by van Wingerden et al. [44]. Measurements of elastic scattering cross-sections have been done by several groups [45-51]. The elastic and inelastic DCSs of $\mathrm{H}_{2}$ were measured at an electron impact energy of $30 \mathrm{keV}$ [52]. Review articles on electron scattering from $\mathrm{H}_{2}$ were presented by Trajmar and McConkey [53] and Morrison et al. [54]. Recently, Anzai et al. have published cross section datasets for electron collisions with $\mathrm{H}_{2}$ [55].

In the intermediate electron energy range, a number of studies have been reported on the absolute elastic differential cross-sections for $\mathrm{H}_{2}[10,12,56-63]$. Furthermore, the energy- and angle-dependent DCSs of $\mathrm{H}_{2}$ by proton impact have been presented in several papers $[64,65]$.

DDCS of ionized electrons can provide a test of the basic formulation of quantum mechanical theory. The main experimental studies on DDCS of $\mathrm{H}_{2}$ by electron impact were reported by several authors [30, 46, 47, 66]. The DDCS of $\mathrm{H}_{2}$ was measured at low energies, including with a dissociation channel [67]. Chatterjee et al. presented a dataset for $8 \mathrm{keV}$ electron impact ionization [68]. Their results have been discussed in the frame of Young type interference effects. Recently, Schulz et al. have measured the DDCS and dissociative ionization of $\mathrm{H}_{2}$ by $75 \mathrm{keV}$ proton impact using angular-dependent measurements [69].

Mostly in the low incident-energy range, electron collision with methane has been studied both experimentally and theoretically. For instance, experimental data on DCSs for low energy electron impact has been discussed in a number of studies [70-79]. On the theoretical side, the literature on low energy electron- $\mathrm{CH}_{4}$ scattering is equally rich. DCSs, momentum transfer cross-sections (MTCSs), and integral cross-sections (ICSs) for elastic electron-methane scattering were calculated at different levels of approximation [80-94].

Comparatively speaking, far fewer studies have been carried out both experimentally and theoretically using intermediate-to-high energies $\left(E_{0}>50 \mathrm{eV}\right)$. The literature for experimental investigations is strongly concentrated on grand total (elastic and inelastic) cross section measurements [95-98]. Some of these works also report the partitioning of the total cross-sections into elastic plus inelastic (ionization 


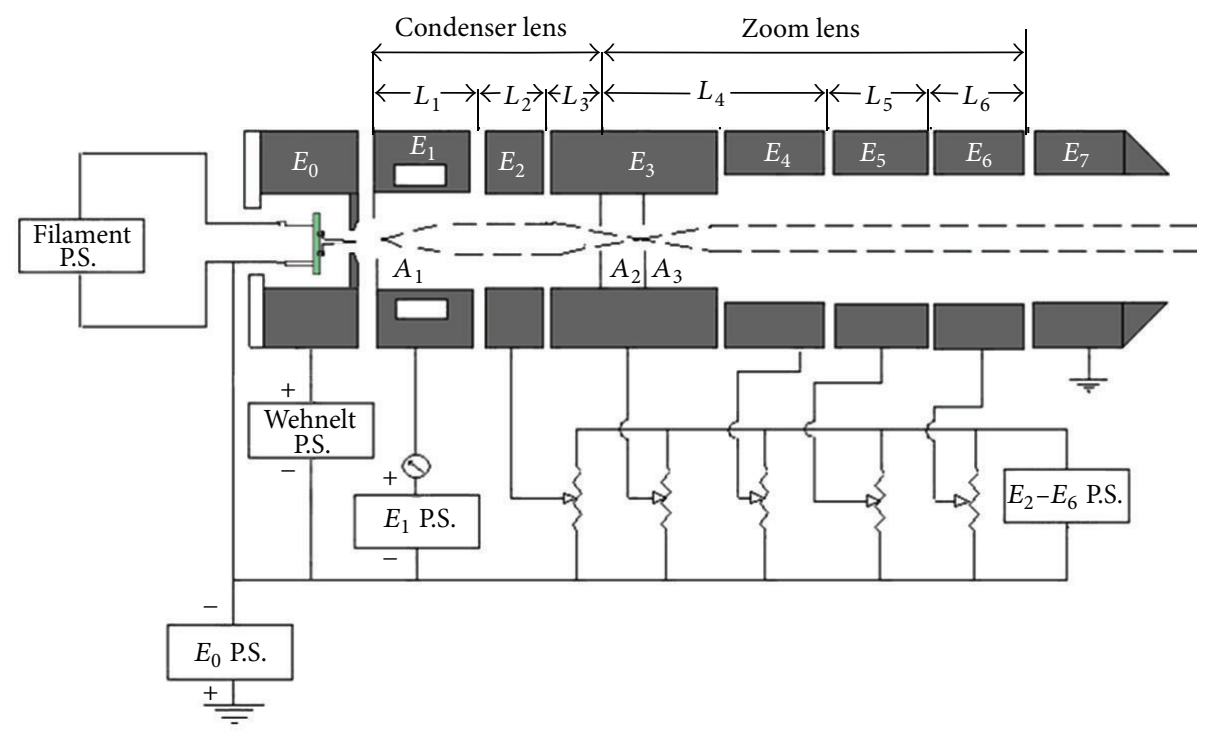

FIgURE 3: The schematic diagram of the electron gun with an electrical circuit.

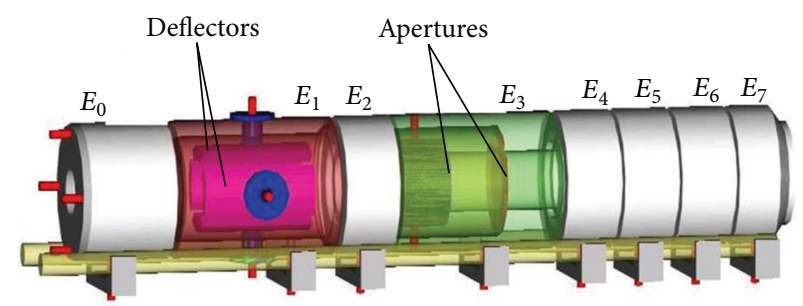

FIgURE 4: The 3D AutoCAD drawing of the electron gun with seven cylindrical elements, apertures, and deflector plates.

and neutral dissociation) cross-sections [96, 98]. Only three sets of absolute measurements of DCSs, ICSs, and MTCSs for elastic electron- $\mathrm{CH}_{4}$ scattering were done by Vuskovic and Trajmar [72] at 20, 30, and $200 \mathrm{eV}$ and by Sakae et al. [99] in the 75-750 eV energy range. Theoretically, elastic electron$\mathrm{CH}_{4}$ cross-sections were done by Dhal et al. [100] for incident energies from 205 to $820 \mathrm{eV}$ and by Jain [81] for incident energies up to $500 \mathrm{eV}$.

The observed cross-sections in electron-methane scattering show a Ramsauer-Townsend minimum around $0.4 \mathrm{eV}$ and a marked increase for higher energies with a maximum at about $8 \mathrm{eV}$ [101-112]. Both of those structures have been well examined by several experiments at different collision energies. Measurements of double differential cross-sections (DDCS) for the ionization of methane molecule are very scarce in the literature $[32,113]$.

In this paper, we reported double differential cross-sections measured using an apparatus originally developed for coincidence measurements of ejected and scattered electrons (i.e., triple differential cross-sections) [114-118]. The same apparatus can also collect data on the angular distribution of the ejected or scattered electrons, simply disabling the coincident circuit. We considered $\mathrm{He}, \mathrm{Ar}, \mathrm{H}_{2}, \mathrm{CH}_{4}$, as typical atom/molecule couples from which we can understand the ionization process in terms of quantum mechanical description.

\section{Experimental Apparatus}

In the Electron Collision (e-COL) Laboratory in Turkey, there are three actively working experimental apparatus. A number of modifications to the original spectrometers have been implemented with different projects granted by Afyon Kocatepe University (AKU), the Scientific and Technological Research Council of Turkey (TUBITAK), the State Planning Organization (DPT), and also a donation from Newcastle University by Prof. Albert Crowe. The experiments described here were performed in Afyon with a recently modified version of an electron spectrometer originally developed in Newcastle [119-122].

The electron spectrometer is a crossed-beams type in which the incident electron beam collides orthogonally with the target gas beam. The electron spectrometer was initially designed and constructed to measure angular and energy correlations between outgoing electrons. The apparatus has been used to measure the triple differential cross-sections for the electron-impact double excitation of helium $[123,124]$, for the electron impact ionization of Argon [115] and $\mathrm{H}_{2}$ [114]. And also the apparatus has the capability to measure differential cross-sections of the ionization of the atoms and molecules with electron impact [125].

The electron beam source, electron energy analyzers, and Faraday cup are situated together in a high-vacuum 


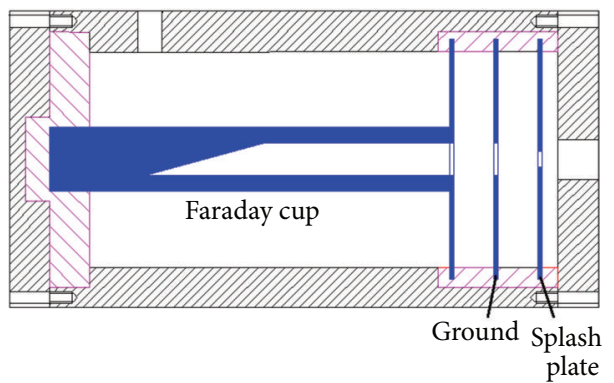

FIgURE 5: The 2D AutoCAD drawing of the Faraday cup.

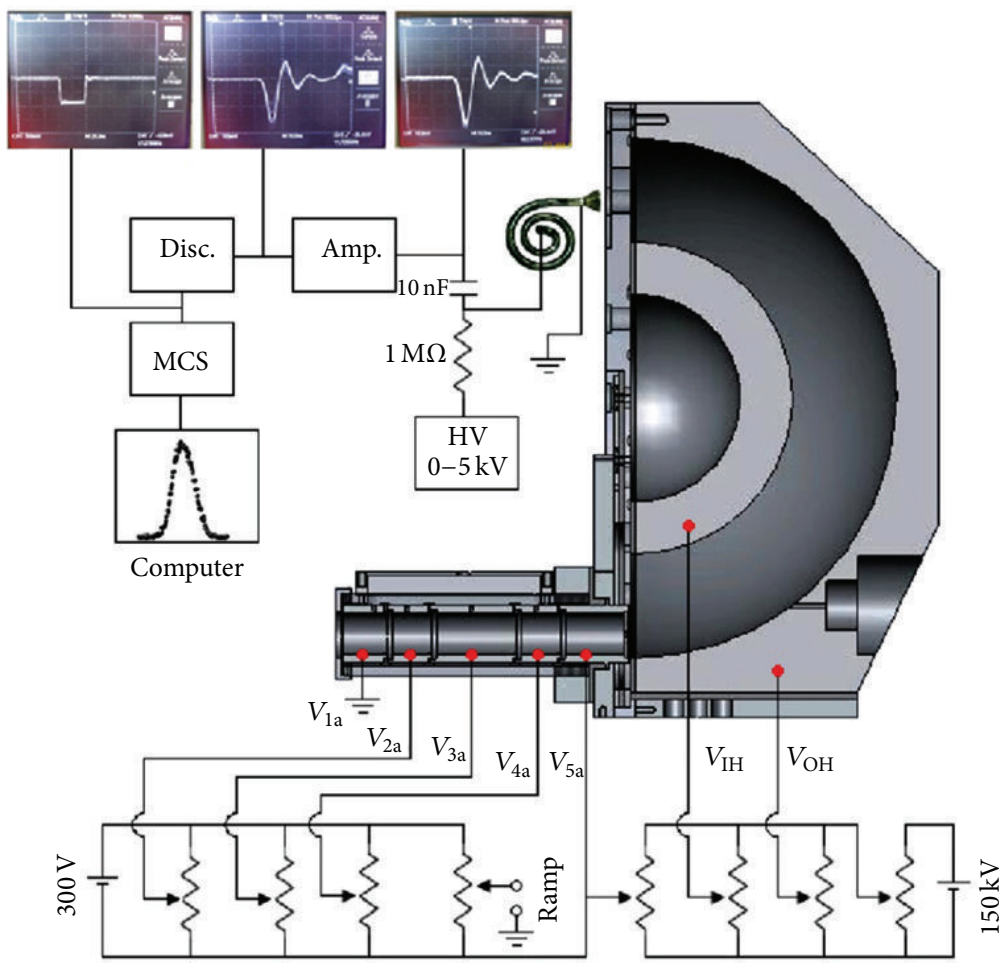

Figure 6: The schematic diagrams of the electron energy analyzer and detector with electric and signal circuits.

chamber [116]. Figure 1 shows the vacuum chamber which is a nonmagnetic stainless steel cylinder, $72 \mathrm{~cm}$ in height, with an internal diameter of $83.5 \mathrm{~cm}$ pumped by a $700 \mathrm{Ls}^{-1}$ Pfeiffer turbo molecular pump backed by a $20 \mathrm{~m}^{3} \mathrm{~h}^{-1}$ Pfeiffer rotary pump. All parts of the electron spectrometer are constructed from dural and brass, which are nonmagnetic and easy to process. The vacuum chamber and flanges are sealed with Viton $\mathrm{O}$-rings and a copper ring, respectively. Vacuum pressure is displayed by a Pfeiffer PKR 251 ion gauge connected to a TC 600 controller. The ultimate pressure, which is recorded and displayed on PC, achieved a background residual pressure of $\sim 8 \times 10^{-8}$ mbar before the target gas beam was let into the vacuum chamber. The target gas is given in vacuum chamber by a gas inlet system consisting of a gas container. The flow of the target gas into interaction region was controlled by a needle valve at entrance to the vacuum chamber and the working pressure was $\sim 6 \times 10^{-6}$ mbar. The target gas beam is shaped through a nozzle, which is also made of brass. The nozzle is $2.5 \mathrm{~mm}$ from the interaction region and is a single capillary type with a diameter of $1 \mathrm{~mm}$.

To reduce external magnetic fields, the inside of the vacuum chamber is shielded by $3 \mathrm{~mm}$-thick $\mu$-metal and, also, the outside of the vacuum chamber surrounded by three Helmholtz coils sets as it is shown in Figure 1. In the interaction region, the external magnetic fields are reduced to less than $0.5 \mathrm{mG}$, as measured with a FLUX meter magnetometer.

The DDCS are measured by the electron energy analyzer rotating around the collision centre in a plane. Figure 2 shows the electron spectrometer which consists of an electron gun, two $180^{\circ}$ hemispherical electron energy analyzers (both analyzers are used for the electron-electron $(e, 2 e)$ coincidence experiments), and a Faraday cup. 


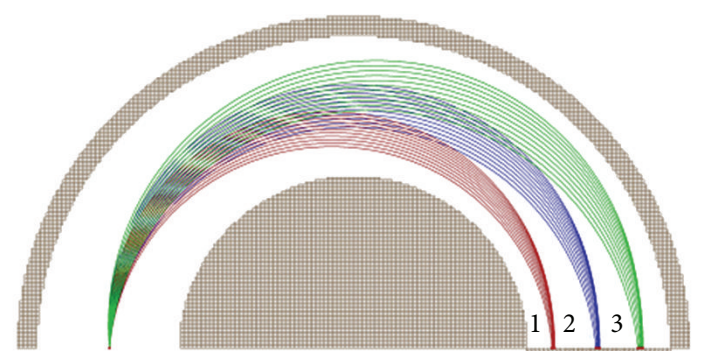

FIGURE 7: SIMION simulations of the pass of different energy electrons through the hemispherical analyzer. The beam of number 1 shows the electron energy of $100 \mathrm{eV}$, number 2 shows the electron energy of $200 \mathrm{eV}$, and number 3 shows the electron energy of $280 \mathrm{eV}$.

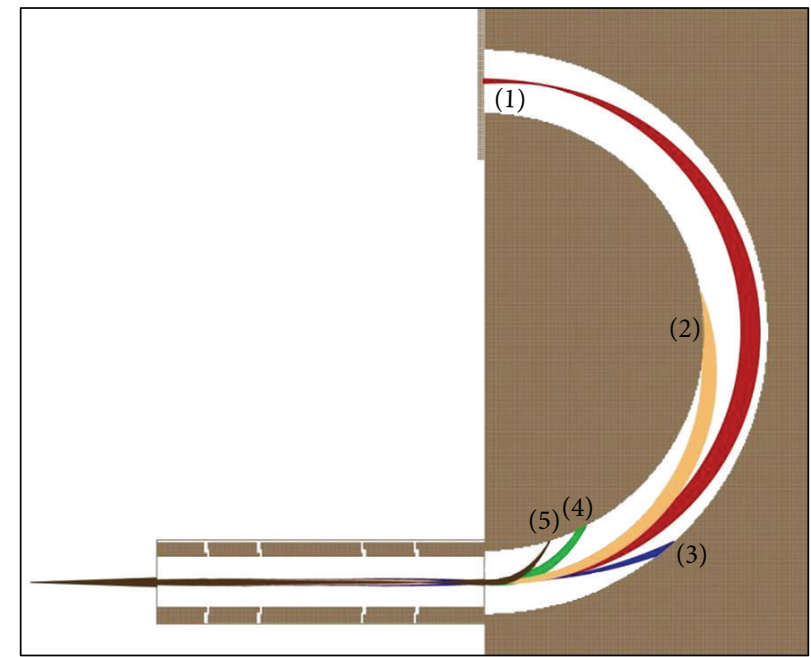

FIGURE 8: Focus of the electron beam at the entrance lens systems and SIMION simulations of electron trajectories with electron energies of (1) - 50, (2) - 45, (3)-70, (4)-30, and (5) $-25 \mathrm{eV}$.

The two electron energy analyzers and Faraday cup are all located on concentric tables which can be rotated independently in the horizontal plane from outside the vacuum chamber by manually mechanic feedthroughs. The electron gun is positioned at the same level as the analyzer and faces the interaction region. Faraday cup, the analyzers, and gas nozzle were carefully aligned using a laser beam in the place of the electron gun. We checked whether the electron analyzers rotated correctly in the scattering plane. In principle, each component of electron spectrometer may move through a full $360^{\circ}$, but this is restricted by the presence of the electron gun and Faraday cup. The angular ranges of the analyzers with respect to the incident beam direction were $-25^{\circ} \leq \theta \leq-130^{\circ}$ and $40^{\circ} \leq \theta \leq 140^{\circ}$ (we used a small Faraday cup for extending angular range).

Figure 3 is a schematic drawing of the electrostatic lens elements and electric circuits of the gun. The Tungsten Hairpin cathode, which is housed in the first element $E_{0}$, is directly heated and gives an energy spread of $\sim 0.5 \mathrm{eV}$ (FWHM).

The beam is accelerated and focused using two groups of cylindrical electrostatic lenses (Figure 3 ). The beam is collimated by three apertures $0.6 \mathrm{~mm}\left(A_{1}\right), 0.4 \mathrm{~mm}\left(A_{2}\right)$, and $0.6 \mathrm{~mm}\left(A_{3}\right)$ in diameter $[116,117,126]$. The $E_{0}$, which has negative potential, accelerates the energy selected beam of low energy electrons up to the impact energy. The final element $E_{7}$ is held at ground potential and so the voltage of the element $E_{0}$ determines the energy of the electron beam. The pairs of $X$ and $Y$ deflector plates are housed in the element $E_{1}$, and these deflector plates lead the beam horizontally or vertically to correct misplacement of the filament or for the effect of magnetic fields on the electron beam. The electron energy can be adjusted from 40 to $400 \mathrm{eV}$, and the electron gun has the capability of focusing to a $1 \mathrm{~mm}$ diameter at the interaction region. Figure 4 shows the 3D AutoCAD drawing of the electron gun. The gun and analyzers are shielded by aluminum boxes grounded at the same point with the chamber and the electronic control panels.

The incident beam current is measured by a Faraday cup located in front of the electron gun. Figure 5 shows that the Faraday cup consists of a cylindrical tube with a $5 \mathrm{~mm}$ aperture and two separate apertures, a splash plate $(2 \mathrm{~mm})$, and a ground aperture $(4 \mathrm{~mm})$.

The Faraday cup and Splash plate current are monitored by Keithley picoammeters. The typical electron-beam currents used in these experiments range from 0.3 to $5 \mu \mathrm{A}$. The Faraday cup is mounted on a concentric disc and rotated around the interaction region. The Faraday cup can move up and down, out of and into the beam. 


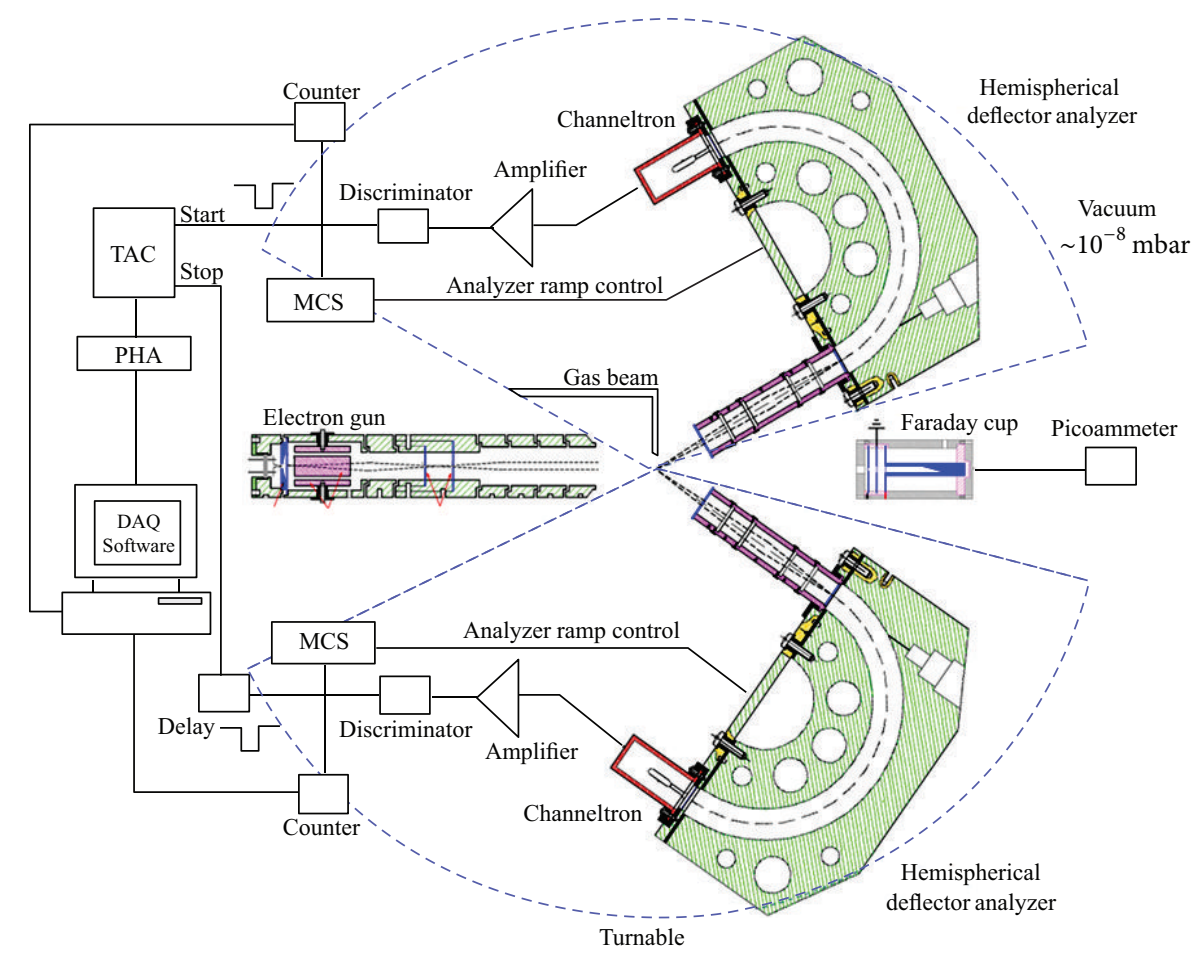

FIGURE 9: The electron gun, energy analyzers—-mounted with detector (CEM) - , Faraday cup, and data accumulation circuit for measurements of DCSs, DDCSs and TDCSs used for electron impact ionization of the gas targets.

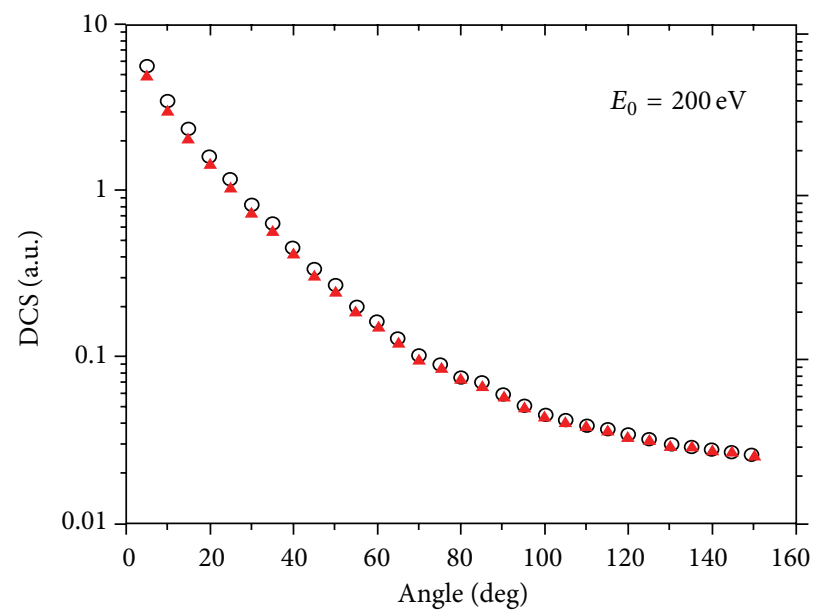

FIGURE 10: Elastic DCS at $200 \mathrm{eV}$ electron impact energy for He (present data (o), Kurepa and Vuskovic (A) [1]).

The electron analyzers were designed for electronelectron coincidence spectrometers for the ionization of the target atom/molecule with electron impact [116]. These analyzers have been used before in several $(e, 2 e)$ experiments by the e-COL group $[114,115,123]$. In this paper, we use one of the analyzers for measuring the cross-sections. Figure 6 shows one of the analyzers with electric and signal circuits. The analyzer consisted of five-element entrance lenses $V_{1 a}$ to $V_{5 a}$ and a $180^{\circ}$ hemispherical deflector. The entrance lens systems focuses on scattered or ejected electrons which are leaving the interaction region to the analyzer, passing energy at the entrance plane. The arrangement of the lens systems made two three-element lenses in a focal mode [118, 127]. The lens systems image the two apertures with a $2 \mathrm{~mm}$ diameter at the entrance and exit of the lens system.

The hemispherical energy analyzers consist of two concentric hemispherical surfaces of radii $R_{1}$ and $R_{2}$. A difference of potential, $V$, which is applied to the hemispherical deflector, produces an electrostatic field, so the electrons follow circular orbits. Figure 7 shows that different energy electrons follow different orbits. The low energy electrons pass the inner hemisphere, while the high energy electrons 


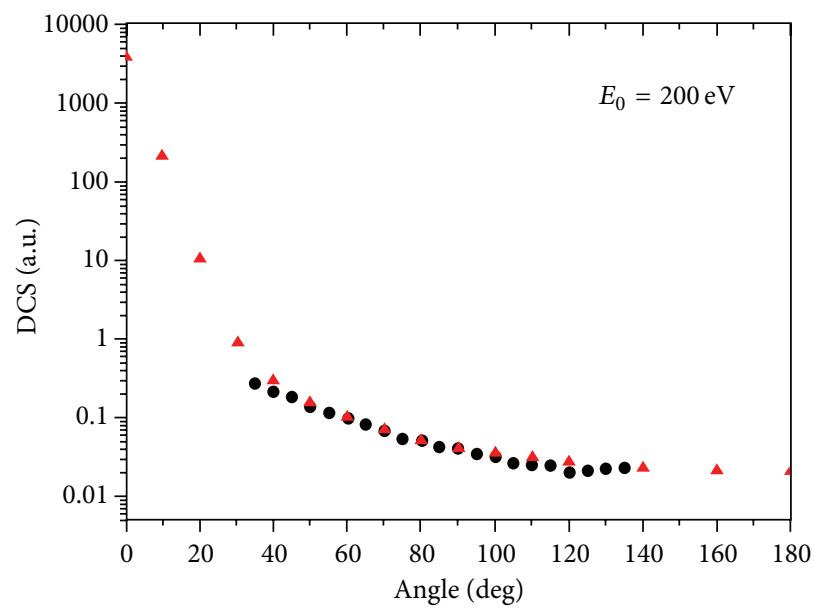

Figure 11: Present measurements $(\bullet)$ of inelastic DCS of Helium for $2^{1} \mathrm{P}$ excitation level at $200 \mathrm{eV}$ electron impact energy in comparison with the results of Fon et al. (A) [4].

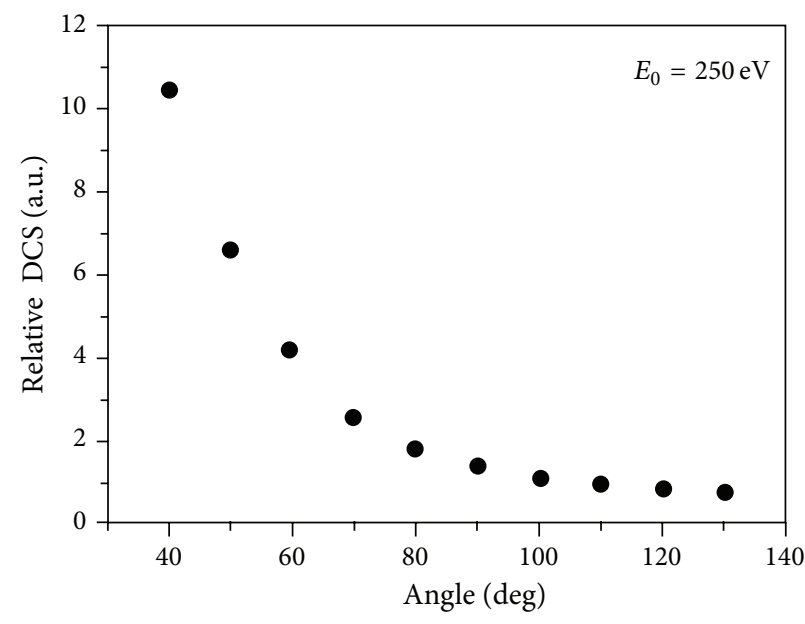

(a)

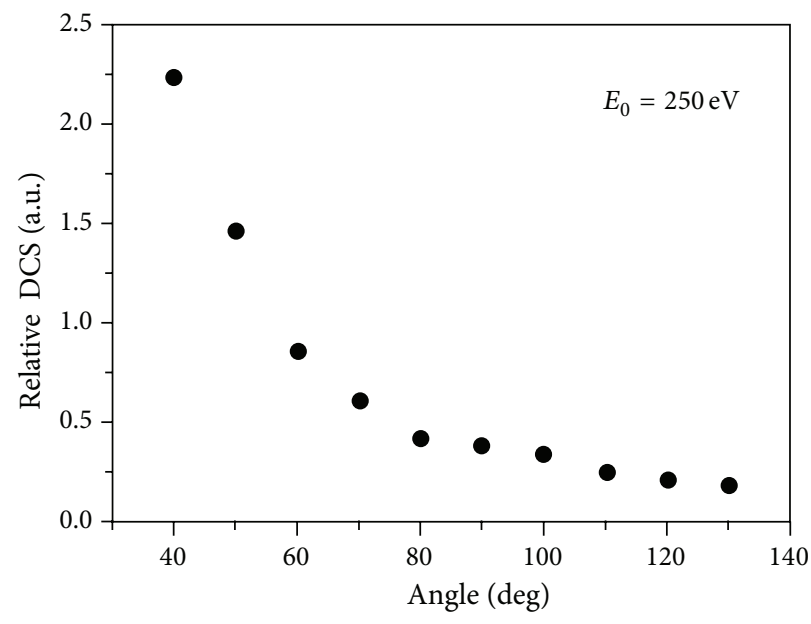

(b)

FIGURE 12: (a) Elastic and (b) inelastic DCS of Helium at $250 \mathrm{eV}$ impact energy.

pass the outer hemisphere. The radii of inner and outer hemispheres are $R_{1}=81.7 \mathrm{~mm}$ and $R_{1}=112.5 \mathrm{~mm}$, and the mean radius is $R_{0}=100 \mathrm{~mm}$. The entrance and exit apertures of the hemisphere are both centered on $R_{0}$. Electrons enter the deflector near the centre of the space between the hemispheres and exit after being deflected by $180^{\circ}$. If the electrons with $E_{0}=e V_{0}$ travel in an orbit of radius $R_{0}$, the voltages on the inner and outer hemispheres are given by $V_{1,2}=V_{0}\left(2 R_{0} / R_{1,2}\right)^{-1}$.

Figure 8 shows SIMION simulations of the trajectories of the electrons with different energies. For example, the electrons of $70 \mathrm{eV}$ knock outer sphere, while the electrons of $25,30,45 \mathrm{eV}$ knock on the inner sphere, and so the electrons of $50 \mathrm{eV}$ achieve the exit aperture (to detector). Energy resolution of the analyzer depends on the energy selection ability of it. The resolution of the conventional hemispherical analyzer is determined by the size of the analyzer and the fringing fields appeared due to using apertures on the exit plane of the spheres $[123,124,126]$.

Following energy selection in the space of the deflector, the electrons are detected by a Photonis-CEM $7018 \mathrm{C} \mathrm{WL}$ channel electron multiplier (CEM). The CEMs are located in front of the exit apertures of the deflectors. The CEM has a channel of $2 \mathrm{~mm}$ internal diameter and a cone of $5.8 \mathrm{~mm}$ diameter, and it is housed in an aluminum grounded box.

A schematic of the electron detection and pulse timing circuits is shown in Figure 9. The signal processing system can measure different kinds of ionization cross-sections of atomic/molecular targets with electron impact. The CEM high voltages are supplied by two ORTEC $5 \mathrm{kV}$ suppliers. The negative pulses from CEM, which has an average amplitude of $\sim 20 \mathrm{mV}$, are amplified to approximately $200 \mathrm{mV}$ by a Philips Scientific 777 Amplifier. The amplified pulses are fed to a Philips Scientific 705 model discriminator for noise 

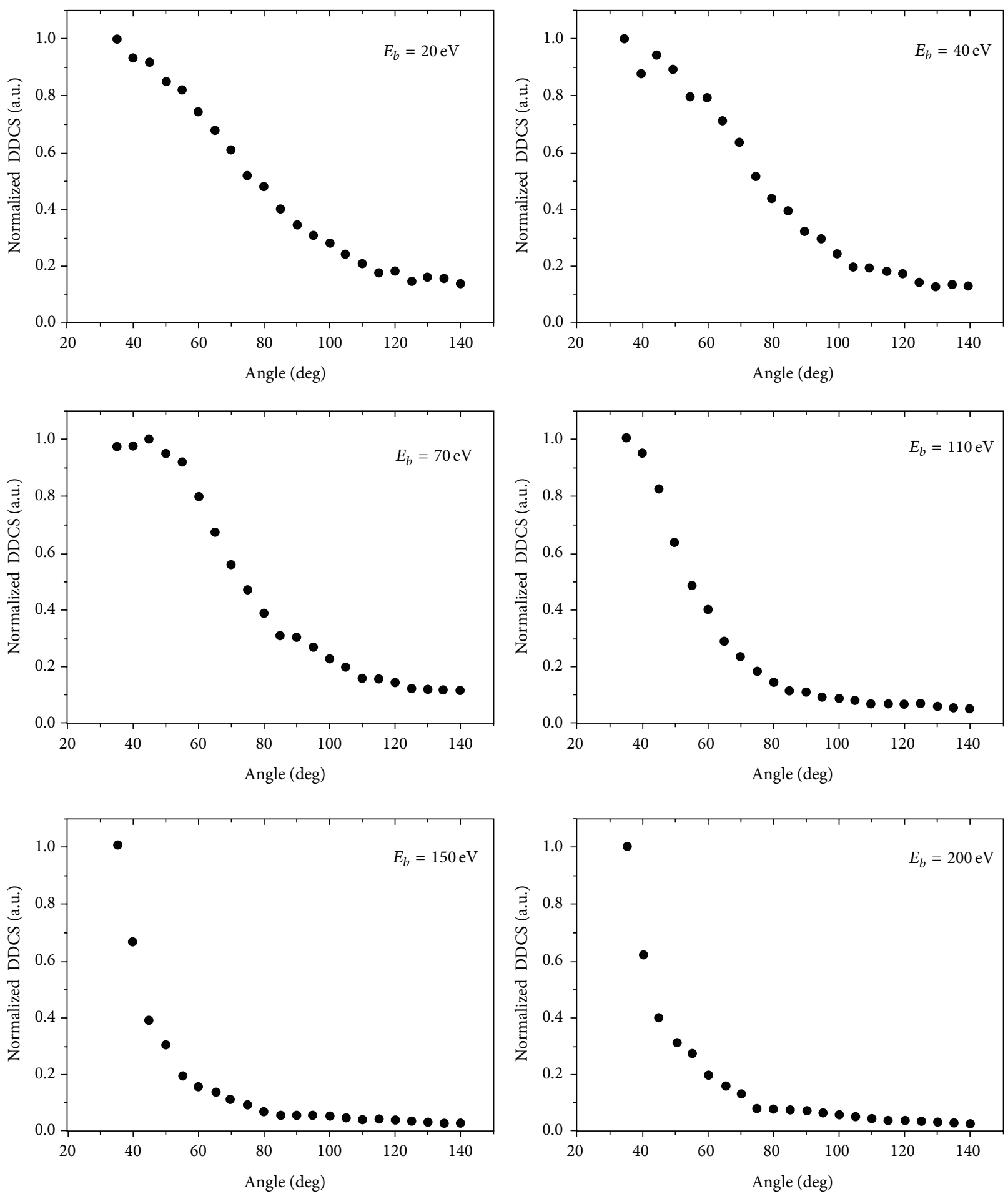

FIGURE 13: Present measurements of DDCS for He at $250 \mathrm{eV}$ electron impact energy for outgoing electron energies between 20-200 eV.

discrimination and $50 \mathrm{~ns}$ wide negative rectangular pulses are obtained. The resulting CEM count rates are monitored by an ORTEC 994 dual counter/timer and recorded to a computer using multichannel scalar (MCS) for noncoincidence measurement, such as energy loss spectra, elastic DCS and DDCS.
The signal going from the second analyzer is processed in the same way using the same process as Previously mentioned. In coincidence mode, we used an ORTEC 566 time-amplitude converter (TAC) and the ORTEC Maestro PC card. The details of the coincidence technique for electron impact 


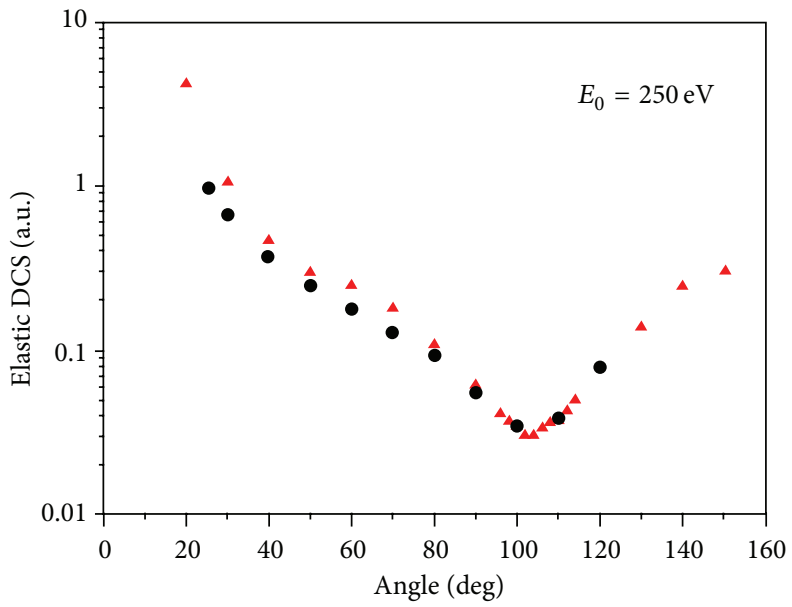

Figure 14: Present results $(\bullet)$ of elastic DCS of Ar in comparison with the data of Williams and Willis $(\boldsymbol{\Delta})$ [37].

ionization are described in the previous works [114, 115, 120]. High voltage power suppliers, the amplifier, the discriminator, the counter, and the TAC are located in NIM bins and pulses of the electronics are transmitted by RG58A/U coaxial and LEMO cables.

\section{Results and Discussion}

4.1. Helium. In Figure 10, we presented the measured elastic DCS of Helium at $200 \mathrm{eV}$ in comparison with the previous work of Kurepa and Vuskovic [1], and an excellent agreement with the experimental data was obtained. At small angles scattering dominated and the value of the cross section decreases slowly with increasing scattering angles.

Similar measurements were also done for inelastic DCS at $200 \mathrm{eV}$ to test the reliability of the present results in comparison to the measurements of Fon et al. [4] (Figure 11). The shape of DCSs in both cases had a strong agreement with the present data between $30^{\circ}$ and $130^{\circ}$.

In Figure 12, experimental elastic and inelastic DCS of He is shown for $250 \mathrm{eV}$. On the basis of the shape of DCS, the data of this study are in agreement with the expected results. However, to the best of our knowledge, there is not a comparable data in the literature for the chosen data sets.

Figure 13 shows the DDCS results of $\mathrm{He}$ at $250 \mathrm{eV}$ impact electron energy for 20 to $150 \mathrm{eV}$ detection electron energies.

The results showed a smooth systematic variation with energy and had a maximum around $50^{\circ}$ at $70 \mathrm{eV}$. This maximum disappears when the outgoing electron energies increase.

4.2. Argon. We measured cross-sections of elastic scattering from $\mathrm{Ar}$ at $250 \mathrm{eV}$ electron impact energy. A critical minimum was observed around $100^{\circ}$, in agreement with the data of Williams and Wills [37] in Figure 14. All noble atoms show parallel structure in the elastic differential cross section at low energies. The DCS of the noble gases show minima at different energies and different angles [127].
Double differential cross-sections (DDCSs) for the single ionization of argon by $250 \mathrm{eV}$ electron impact were measured for the ejection energy range of 10-200 eV (Figure 15).

The high energy ejected electrons are emitted in the forward direction and the lower energy ejected electrons are mostly ejected isotropically in all directions. Ejected electrons with higher energies produce the same structure in the DDCSs due to a binary collision between the incident electron and an electron from the target.

4.3. $\mathrm{H}_{2}$. In this study, we measured the energy and angular distributions of ejected electrons for the ionization of the simplest molecule, $\mathrm{H}_{2}$. Reliable collision cross section data on $\mathrm{e}-\mathrm{H}_{2}$ are especially needed for the study of planetary atmosphere. The elastic and inelastic DCS and DDCS were measured for the incident energy of $250 \mathrm{eV}$. In Figure 16, we present the measured elastic DCS of $\mathrm{H}_{2}$ at $250 \mathrm{eV}$. At this energy, we could not find any reliable experimental DCS data to be compared with the findings of our study. The measured DCSs show a maximum at low scattering angles and decrease as the scattering angle increases. However, that increase seen in the He DCS results at high scattering angles was not observed in the $\mathrm{H}_{2}$ results.

Figure 17 shows the present measurements of DDCS as a function of the angle of electron detection $\theta_{b}$ varying between $40^{\circ}$ and $130^{\circ}$, for detected electron energies of 50 and $30 \mathrm{eV}$, respectively, at $250 \mathrm{eV}$ incident electron energy. Figure 17 also shows the comparison of the data of Shyn and Sharp (1981) for DDCS at 30 and $50 \mathrm{eV}$ electron detection energies. The measurements obtained from our study for these two energies were compared with the data of Shyn and Sharp (1981), and looking at the results of DDCS, there was a broad general agreement. In this case, there was much stronger scattering in the forward direction and a more rapid decrease in the DDCS with increasing angle. A broad maximum around $60^{\circ}$ was seen in the results of our study as well as in the data of Shyn and Sharp $[46,47]$. The measured values of DDCS were relatively higher for lower detection electron 

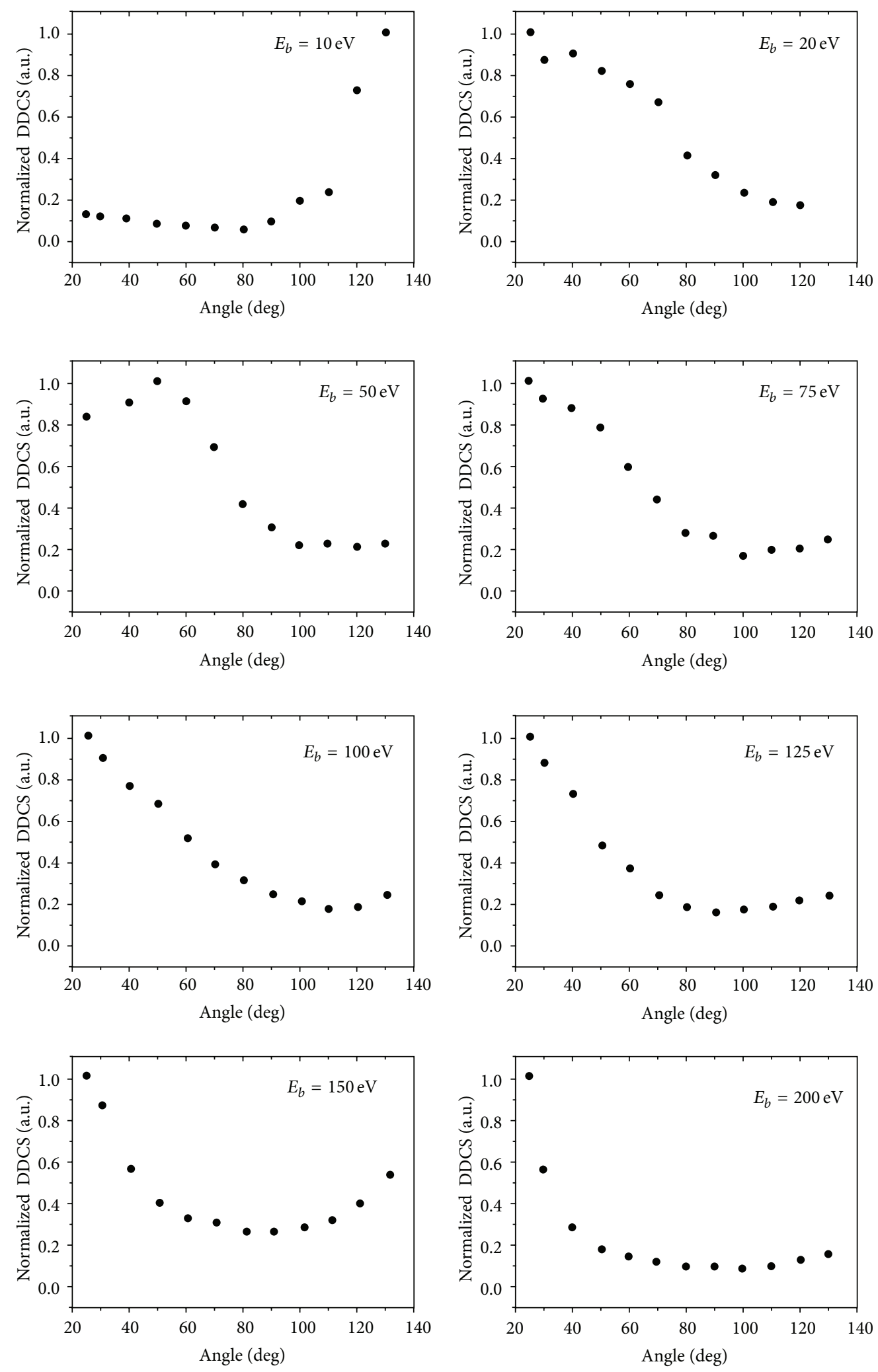

FIGURE 15: Present measurements of DDCS for Ar at $250 \mathrm{eV}$ electron impact energy for 10-200 eV detection electron energies. 


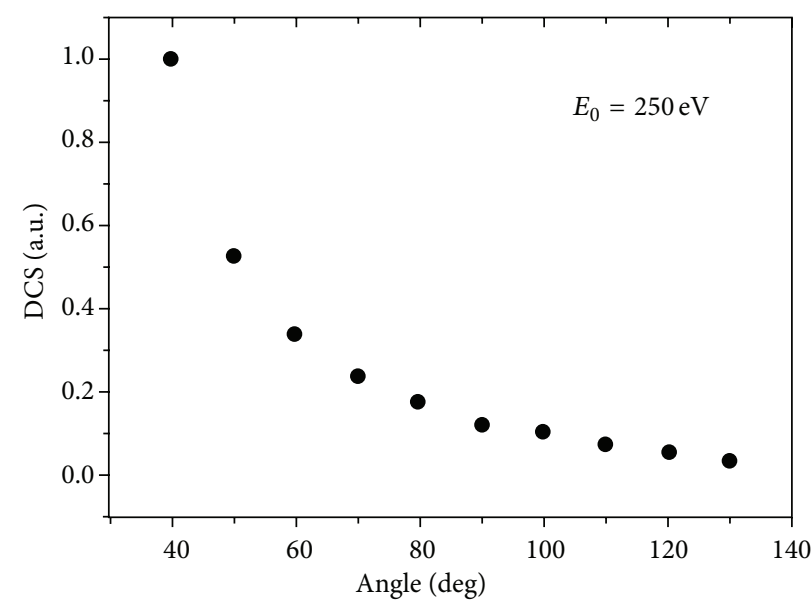

FIgURE 16: Elastic DCS at $250 \mathrm{eV}$ electron impact energy for $\mathrm{H}_{2}$.
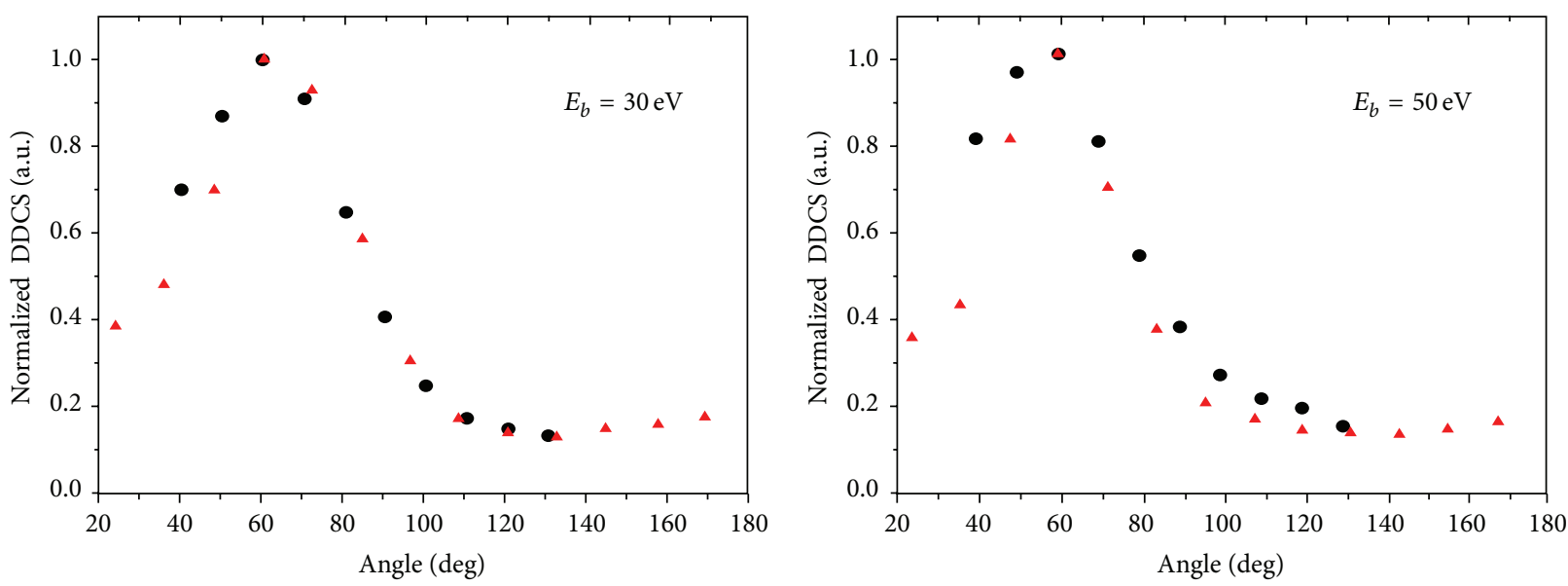

Figure 17: Present measurements of (•) DDCS for $\mathrm{H}_{2}$ at $250 \mathrm{eV}$ electron impact energy for 30 and $50 \mathrm{eV}$ detection electron energies, respectively. The symbol ( $\Delta$ ) shows the published results of DDCS from Shyn et al. [47].

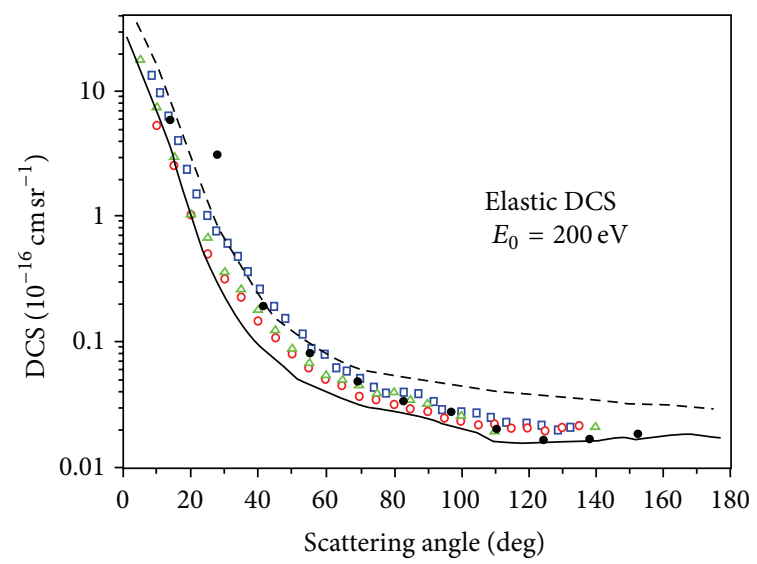

(a)

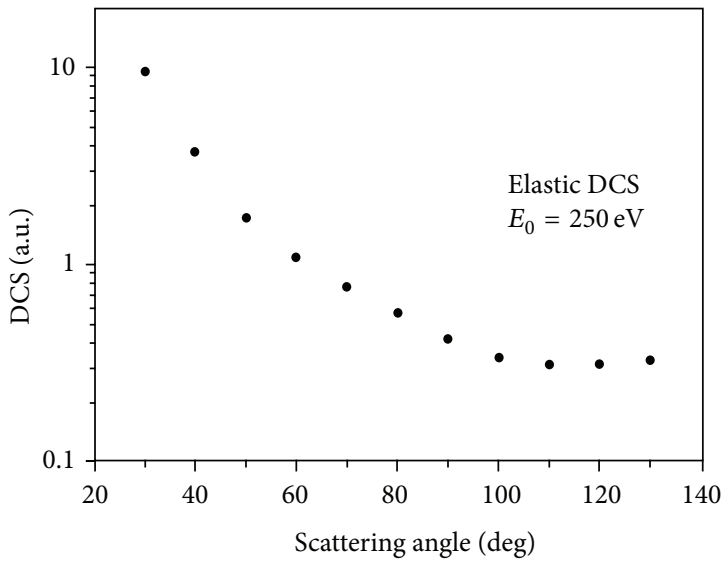

(b)

FIGURE 18: DCSs for elastic e- $\mathrm{CH}_{4}$ collision at (a) $200 \mathrm{eV}$ and (b) $250 \mathrm{eV}$. Full circles present our experimental results; open circles, experimental data of Iga et al. [90]; open squares, experimental data of Vuskovic and Trajmar [72]; open triangles, experimental data of Sakae et al. [99]; solid line, theoretical results of Iga et al. [90]; dashed line, theoretical results of Dhal et al. [100]. 

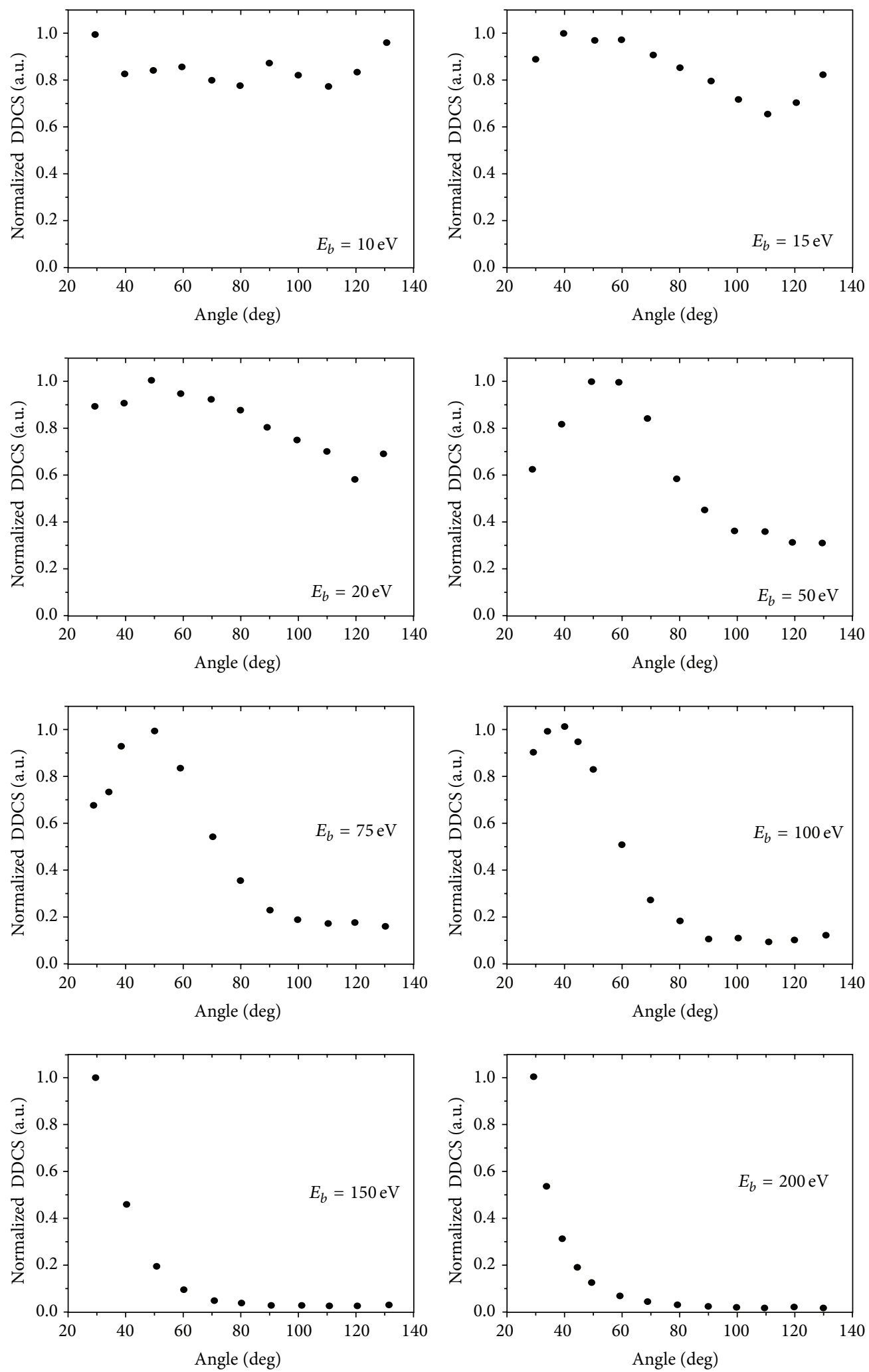

Figure 19: Present measurements of DDCSs of $\mathrm{CH}_{4}$ for $10-200 \mathrm{eV}$ detection electron energies. 
angles and higher detection electron energies since electrons having higher energies were rather scattered in the forward direction.

4.4. $\mathrm{CH}_{4}$. As an experimental confirmation of our results, elastic differential cross section measurements of methane for $200 \mathrm{eV}$ incident electrons were taken and compared with the previous results $[72,90,99,100]$ (Figure 18(a)). The agreement between the present and previous data was good. And also in this study, elastic differential cross section of methane at $250 \mathrm{eV}$ firstly was measured (Figure 18(b)).

The DDCS results for $250 \mathrm{eV}$ incident electrons on a methane molecule are given in Figure 19. The analyzer was adjusted to detect $10-225 \mathrm{eV}$ outgoing electrons after collision. A maximum was observed for 50,75 , and $100 \mathrm{eV}$ detection energies. This is a consequence of the binary character of the collision. Since most of the faster electrons are scattered into the forward direction, the maximum shows that the angle between the scattered and ejected electrons for most of the collision processes is $\theta<90^{\circ}$.

\section{Conclusion}

DDCS experiments give important results about the ionization events in atoms and molecules. DDCS measurements are fundamental studies to which other measurements may be related. As an experimental confirmation of our results, elastic differential cross section measurements of $\mathrm{He}, \mathrm{Ar}$, $\mathrm{H}_{2}$, and $\mathrm{CH}_{4}$ for $250 \mathrm{eV}$ incident electrons were taken and compared with the previous results. It is expected that these results will further aid our understanding of the ionization mechanisms of small molecules.

\section{Acknowledgments}

This work was supported by the Scientific and Technological Research Council of Turkey (TUBITAK) through Grants 109T738, 109T722; State Planning Organization (DPT) 2001K120140, and Afyon Kocatepe University Scientific Research Projects Coordination Funds (BAPK).

\section{References}

[1] M. V. Kurepa and L. Vuskovic, "Differential cross sections of 100,150 and $200 \mathrm{eV}$ electrons elastically scattered in helium," Journal of Physics B, vol. 8, no. 12, pp. 2067-2078, 1975.

[2] T. W. Shyn, "Angular distribution of electrons elastically scattered from gases: 2-400 eV on He. i," Physical Review A, vol. 22, no. 3, pp. 916-922, 1980

[3] S. Trajmar, D. F. Register, D. C. Cartwright, and G. Csanak, "Differential and integral cross sections for electron impact excitation of the $n^{3} S, n^{1} S$ and $n^{3}(n=2,3)$ levels in He," Journal of Physics B, vol. 25, no. 22, p. 4889, 1992.

[4] W. C. Fon, K. A. Berrington, and A. Hibbert, "The elastic scattering of electrons from inert gases. I. Helium," Journal of Physics $B$, vol. 14, no. 2, pp. 307-321, 1981.

[5] J. P. Bromberg, "Absolute differential cross sections of electrons elastically scattered by the rare gases. I. Small angle scattering between 200 and 700 eV," The Journal of Chemical Physics, vol. 61, no. 3, pp. 963-969, 1974.

[6] S. K. Sethuraman, J. A. Rees, and J. R. Gibson, "Angular differential cross sections for elastically scattered electrons in helium," Journal of Physics B, vol. 7, no. 13, pp. 1741-1747, 1974.

[7] D. Andrick and A. Bitsch, "Experimental investigation and phase shift analysis of low-energy electron-helium scattering," Journal of Physics B, vol. 8, no. 3, pp. 393-410, 1975.

[8] R. H. J. Jansen, F. J. de Heer, H. J. Luyken, B. van Wingerden, and H. J. Blaauw, "Absolute differential cross sections for elastic scattering of electrons by helium, neon, argon and molecular nitrogen," Journal of Physics B, vol. 9, no. 2, pp. 185-212, 1976.

[9] J. W. McConkey and J. A. Preston, "Differential elastic scattering of electrons by the rare gases. I. Helium," Journal of Physics B, vol. 8, no. 1, pp. 63-74, 1975.

[10] S. K. Srivastava, A. Chutjian, and S. Trajmar, "Absolute elastic differential electron scattering cross sections in the intermediate energy region. I. H2," The Journal of Chemical Physics, vol. 63, no. 6, pp. 2659-2665, 1975.

[11] N. F. Mott, “The collision between two electrons," Proceedings of the Royal Society A, vol. 126, no. 801, pp. 259-267, 1930.

[12] S. P. Khare and B. L. Moiseiwitsch, "The angular distribution of electrons elastically scattered by helium atoms and by hydrogen molecules," Proceedings of the Physical Society, vol. 85, no. 5, pp. 821-839, 1965.

[13] R. W. LaBahn and J. Callaway, "Distortion effects in the elastic scattering of 100 - to $400-\mathrm{eV}$ electrons from helium," Physical Review, vol. 180, no. 1, pp. 91-96, 1969.

[14] R. W. LaBahn and J. Callaway, "Differential cross sections for the elastic scattering of 1- to 95-eV electrons from helium," Physical Review A, vol. 2, no. 2, pp. 366-369, 1970.

[15] D. P. Dewangan and H. R. J. Walters, "The elastic scattering of electrons and positrons by helium and neon: the distorted-wave second Born approximation," Journal of Physics B, vol. 10, no. 4, pp. 637-661, 1977.

[16] R. S. Oberoi and R. K. Nesbet, "Inelastic scattering of electrons by helium," Physical Review A, vol. 8, no. 6, pp. 2969-2979, 1973.

[17] K. H. Winters, C. D. Clark, B. H. Bransden, and J. P. Coleman, "The use of second order potentials in the theory of scattering of charged particles by atoms. VII. the partial wave formalism and elastic scattering of electrons by hydrogen and helium," Journal of Physics B, vol. 7, no. 7, pp. 788-798, 1974.

[18] Y. K. Kim, "Energy distribution of secondary electrons. II. Normalization and extrapolation of experimental data," Radiation Research, vol. 64, no. 2, pp. 205-216, 1975.

[19] F. W. Byron Jr. and C. J. Joachain, "Elastic scattering of electrons and positrons by atomic hydrogen and helium at intermediate and high energies," Journal of Physics B, vol. 10, no. 2, pp. 207226, 1977

[20] T. T. Gien, "Elastic scattering of electrons by helium at intermediate energies," Physical Review A, vol. 16, no. 5, pp. 1793-1798, 1977.

[21] I. Bray, D. V. Fursa, and I. E. McCarthy, "Calculation of electronhelium scattering at 40 eV," Physical Review A, vol. 51, no. 1, pp. 500-503, 1995.

[22] D. V. Fursa and I. Bray, "Calculation of electron-helium scattering," Physical Review A, vol. 52, no. 2, pp. 1279-1297, 1995.

[23] R. Biswas and C. Sinha, "Double- and triple-differential cross sections for electron-impact ionization of helium," Physical Review A, vol. 51, no. 5, pp. 3766-3772, 1995. 
[24] R. Biswas and C. Sinha, "Double- and single-differential and total ionization cross sections for electron-impact ionization of a helium atom," Physical Review A, vol. 54, no. 4, pp. 2944-2950, 1996.

[25] S. Brajamani, N. R. Singh, M. Babuyaima, and P. S. Mazumdar, "Cold cardioplegia and the $\mathrm{K}^{+}$channel modulator aprikalim (RP 52891): improved cardioprotection in isolated ischemic rabbit hearts," Canadian Journal of Physiology and Pharmacology, vol. 72, no. 2, pp. 126-132, 1994.

[26] I. E. McCarthy and X. Zhang, "Distorted-wave Born approximation for electron-helium double differential ionisation cross sections," Journal of Physics B, vol. 22, no. 13, pp. 2189-2193, 1989.

[27] J. Röder, H. Ehrhardt, I. Bray, and D. V. Fursa, "Absolute double differential cross sections for electron-impact ionization of helium," Journal of Physics B, vol. 30, p. 1309, 1997.

[28] R. Müller-Fiedler, K. Jung, and H. Ehrhardt, "Double differential cross sections for electron impact ionisation of helium," Journal of Physics B, vol. 19, no. 8, pp. 1211-1229, 1986.

[29] T. W. Shyn and W. E. Sharp, "Doubly differential cross sections of secondary electrons ejected from gases by electron impact: 50-300 eV on helium," Physical Review A, vol. 19, no. 2, pp. 557$567,1979$.

[30] R. D. DuBois and M. E. Rudd, "Absolute doubly differential cross sections for ejection of secondary electrons from gases by electron impact. II. 100-500-eV electrons on neon, argon, molecular hydrogen, and molecular nitrogen," Physical Review A, vol. 17, no. 3, pp. 843-848, 1978.

[31] M. E. Rudd and R. D. DuBois, "Absolute doubly differential cross sections for ejection of secondary electrons from gases by electron impact. I. 100- and 200-eV electrons on helium," Physical Review A, vol. 16, no. 1, pp. 26-32, 1977.

[32] C. B. Opal, E. C. Beaty, and W. K. Peterson, "Tables of secondary-electron-production cross sections," Atomic Data and Nuclear Data Tables, vol. 4, pp. 209-253, 1972.

[33] L. Avaldi, R. Camilloni, E. Fainelli, and G. Stefani, "Absolute double differential ionization cross-section for electron impact: He," Il Nuovo Cimento D, vol. 9, no. 1, pp. 97-113, 1987.

[34] D. Cvejanovic and A. Crowe, "Differential cross sections for elastic scattering of electrons from argon and krypton as a continuous function of energy," Journal of Physics B, vol. 30, no. 12, pp. 2873-2887, 1997.

[35] R. D. Dubois and M. E. Rudd, "Absolute differential cross sections for 20-800 eV electrons elastically scattered from argon," Journal of Physics B, vol. 8, no. 9, p. 1474, 1975.

[36] L. Vuskovic and M. V. Kurepa, "Differential cross sections of 60$150 \mathrm{eV}$ electrons elastically scattered in argon," Journal of Physics $B$, vol. 9, no. 5, pp. 837-842, 1976.

[37] J. F. Williams and B. A. Willis, "The scattering of electrons from inert gases. I. Absolute differential elastic cross sections for argon atoms," Journal of Physics B, vol. 8, no. 10, p. 1670, 1975.

[38] S. N. Nahar and J. M. Wadehra, "Elastic scattering of positrons and electrons by argon," Physical Review A, vol. 35, no. 5, pp. 2051-2064, 1987.

[39] A. R. Milosavljević, S. Telega, D. Šević, J. E. Sienkiewicz, and B. P. Marinković, "Elastic electron scattering by argon in the vicinity of the high-energy critical minimum," Radiation Physics and Chemistry, vol. 70, no. 6, pp. 669-676, 2004.

[40] R. Hippler, K. Saeed, I. McGregor, and H. Kleinpoppen, "Energy dependence of characteristic and bremsstrahlung cross sections of argon induced by electron bombardment at low energies," Zeitschrift für Physik A Atoms and Nuclei, vol. 307, no. 1, pp. 8387, 1982.
[41] M. A. Chaudhry, A. J. Duncan, R. Hippler, and H. Kleinpoppen, "Partial doubly differential cross sections for multiple ionization of argon, krypton, and xenon atoms by electron impact," Physical Review A, vol. 39, no. 2, pp. 530-536, 1989.

[42] A. C. F. Santos, A. Hasan, T. Yates, and R. D. DuBois, "Doubly differential measurements for multiple ionization of argon by electron impact: comparison with positron impact and photoionization," Physical Review A, vol. 67, no. 5, Article ID 052708, 6 pages, 2003.

[43] B. R. Yates and M. A. Khakoo, "Near-threshold electron-impact doubly differential cross sections for the ionization of argon and krypton," Physical Review A, vol. 83, no. 4, Article ID 042712, 2011.

[44] B. van Wingerden, F. J. de Heer, E. Weigold, and K. J. Nygaard, "Elastic scattering of electrons by molecular and atomic hydrogen," Journal of Physics B, vol. 10, no. 7, pp. 1345-1362, 1977.

[45] J. F. Williams, "Electron scattering from atomic hydrogen. III. Absolute differential cross sections for elastic scattering of electrons of energies from 20 to $680 \mathrm{eV}$,' Journal of Physics B, vol. 8, no. 13, p. 2191, 1975.

[46] T. W. Shyn and W. E. Sharp, "Angular distributions of electrons elastically scattered from $\mathrm{H}_{2}$," Physical Review A, vol. 24, no. 4, pp. 1734-1740, 1981.

[47] T. W. Shyn, W. E. Sharp, and Y.-K. Kim, "Doubly differential cross sections of secondary electrons ejected from gases by electron impact: 25-250 eV on H2," Physical Review A, vol. 24, no. 1, pp. 79-88, 1981.

[48] H. Nishimura and A. Danjo, "Differential cross section of electron scattering from molecular hydrogen. II. b3 $\sum \mathrm{u}+$ excitation," Journal of the Physical Society of Japan, vol. 55, no. 9, pp. 30313036, 1986.

[49] M. A. Khakoo and S. Trajmar, "Elastic electron scattering cross sections for molecular hydrogen," Physical Review A, vol. 34, no. 1, pp. 138-145, 1986.

[50] M. J. Brunger, S. J. Buckman, D. S. Newman, and D. T. Alle, "Elastic scattering and rovibrational excitation of $\mathrm{H}_{2}$ by lowenergy electrons," Journal of Physics B, vol. 24, no. 6, p. 1435, 1991.

[51] M. J. Brunger, S. J. Buckman, L. J. Allen, I. E. McCarthy, and K. Ratnavelu, "Elastic electron scattering from helium: absolute experimental cross sections, theory and derived interaction potentials," Journal of Physics B, vol. 25, no. 8, p. 1823, 1992.

[52] Y. Zhang, A. W. Ross, and M. Fink, "High-energy electron scattering study of molecular hydrogen," Physical Review A, vol. 43, no. 7, pp. 3548-3552, 1991.

[53] S. Trajmar and J. W. McConkey, "Benchmark measurements of cross sections for electron collisions: analysis of scattered electrons," Advances in Atomic, Molecular and Optical Physics, vol. 33, pp. 63-96, 1994.

[54] M. A. Morrison, R. W. Crompton, B. C. Saha, and Z. Petrovic, "Near-threshold rotational and vibrational excitation of $\mathrm{H}_{2}$ by electron impact: theory and experiment," Australian Journal of Physics, vol. 40, no. 3, pp. 239-282, 1987.

[55] K. Anzai, H. Kato, M. Hoshino et al., "Cross section data sets for electron collisions with $\mathrm{H}_{2}, \mathrm{O}_{2}, \mathrm{CO}, \mathrm{CO}_{2}, \mathrm{~N}_{2} \mathrm{O}$ and $\mathrm{H}_{2} \mathrm{O}$," European Physical Journal D, vol. 66, article 36, 2012.

[56] R. A. Bonham and T. Iijima, "The theory of electron scattering from molecules. II. Molecular hydrogen," Journal of Physical Chemistry, vol. 67, no. 11, pp. 2266-2272, 1963.

[57] A. L. Ford and J. C. Browne, "Elastic scattering of electrons by $\mathrm{H}_{2}$ in the born approximation," Chemical Physics Letters, vol. 20, no. 3, pp. 284-290, 1973. 
[58] J. W. Liu and V. H. Smith Jr., "The differential cross section for elastic scattering of electrons by $\mathrm{H}_{2}$ in the first Born approximation," Journal of Physics B, vol. 6, no. 10, p. L275, 1973.

[59] H. S. W. Massey and C. B. O. Mohr, "The collision of electrons with molecules," Proceedings of the Royal Society A, vol. 135, no. 826, pp. 258-275, 1932.

[60] P. K. Bhattacharyya and A. S. Ghosh, "Elastic scattering of electrons by hydrogen molecules using the eikonal approximation," Physical Review A, vol. 12, no. 2, pp. 480-485, 1975.

[61] P. K. Bhattacharyya and A. S. Ghosh, "Application of the eikonal amplitude to rotational excitations of diatomic molecules by electron impact," Physical Review A, vol. 14, no. 4, pp. 1587-1594, 1976.

[62] C. R. Lloyd, P. J. O. Teubner, E. Weigold, and B. R. Lewis, “Differential cross sections for the elastic scattering of electrons from atomic hydrogen. II. Medium energies," Physical Review A, vol. 10, no. 1, pp. 175-181, 1974.

[63] P. Gupta and S. P. Khare, "Elastic scattering of electrons by molecular hydrogen for incident energies 100-2000 eV," The Journal of Chemical Physics, vol. 68, no. 5, pp. 2193-2198, 1978.

[64] L. H. Toburen and W. E. Wilson, "Distributions in energy and angle of electrons ejected from molecular hydrogen by 0.3-1.5MeV protons," Physical Review A, vol. 5, no. 1, pp. 247-256, 1972.

[65] M. E. Rudd, D. Gregoire, and J. B. Crooks, "Comparison of experimental and theoretical values of cross sections for electron production by proton impact," Physical Review A, vol. 3, no. 5, pp. 1635-1640, 1971.

[66] S. Tahira and N. Oda, "Calculation of double differential cross sections for ionizing collisions of electrons with helium by Born approximation and binary encounter theory," Journal of the Physical Society of Japan, vol. 35, no. 2, pp. 582-591, 1973.

[67] A. H. Al-Nasir, M. A. Chaudhry, A. J. Duncan, R. Hippler, and H. Kleinpoppen, "Doubly differential cross section for the ionization of the hydrogen molecule by the impact of $100-\mathrm{eV}$ electrons," Physical Review A, vol. 47, no. 4, pp. 2922-2926, 1993.

[68] S. Chatterjee, A. N. Agnihotri, C. R. Stia, O. A. Fojón, R. D. Rivarola, and L. C. Tribedi, "Bethe binary-encounter peaks in the double-differential cross sections for high-energy electronimpact ionization of $\mathrm{H} 2$ and He," Physical Review A, vol. 82, no. 5, Article ID 052709, 2010.

[69] M. Schulz, K. Egodapitiya, S. Sharma, and A. C. Laforge, "Scattering angle dependence of double differential cross sections for dissociative ionization of $\mathrm{H}_{2}$ by proton impact," Journal of Physics: Conference Series, vol. 388, part 10, Article ID 102028, 2012.

[70] P. J. Curry, W. R. Newell, and A. C. H. Smith, "Elastic and inelastic scattering of electrons by methane and ethane," Journal of Physics B, vol. 18, no. 11, pp. 2303-2318, 1985.

[71] H. Tanaka, T. Okada, L. Boesten, T. Suzuki, T. Yamamoto, and M. Kubo, "Differential cross sections for elastic scattering of electrons by $\mathrm{CH}_{4}$ in the energy range of 3 to $20 \mathrm{eV}$," Journal of Physics B, vol. 15, no. 18, pp. 3305-3319, 1982.

[72] L. Vuskovic and S. Trajmar, "Electron impact excitation of methane," The Journal of Chemical Physics, vol. 78, no. 8, pp. 4947-4951, 1983.

[73] W. Sohn, K.-H. Kochem, K.-M. Scheuerlein, K. Jung, and H. Ehrhardt, "Elastic electron scattering from $\mathrm{CH}_{4}$ for collision energies between 0.2 and 5 eV," Journal of Physics B, vol. 19, no. 21, pp. 3625-3632, 1986.

[74] T. W. Shyn and T. E. Cravens, "Angular distribution of electrons elastically scattered from $\mathrm{CH}_{4}$," Journal of Physics $B$, vol. 23, no. 2, p. 293, 1990.
[75] L. Boesten and H. Tanaka, "Elastic DCS for e+ $\mathrm{CH}_{4}$ collisions, 1.5-100 eV," Journal of Physics B, vol. 24, no. 4, p. 821, 1991.

[76] I. Kanik, S. Trajmar, and J. C. Nickel, "Total electron scattering and electronic state excitations cross sections for $\mathrm{O}_{2}, \mathrm{CO}$, and $\mathrm{CH}_{4}$," Journal of Geophysical Research, vol. 98, pp. 7447-7460, 1993.

[77] B. Mapstone and W. R. Newell, "Elastic differential electron scattering from $\mathrm{CH}_{4}, \mathrm{C}_{2} \mathrm{H}_{4}$ and $\mathrm{C}_{2} \mathrm{H}_{6}$," Journal of Physics $B$, vol. 25, no. 2, p. 491, 1992.

[78] C. T. Bundschu, J. C. Gibson, R. J. Gulley et al., "Low-energy electron scattering from methane," Journal of Physics B, vol. 30, no. 9, pp. 2239-2259, 1997.

[79] H. Cho, Y. S. Park, E. A. Castro et al., "A comparative experimental-theoretical study on elastic electron scattering by methane," Journal of Physics B, vol. 41, no. 4, Article ID 045203, 2008.

[80] M. A. P. Lima, T. L. Gibson, W. M. Huo, and V. McKoy, "Studies of electron-polyatomic-molecule collisions: applications to eCH4," Physical Review A, vol. 32, no. 5, pp. 2696-2701, 1985.

[81] A. Jain, "Total (elastic+absorption) cross sections for e- $\mathrm{CH}_{4}$ collisions in a spherical model at $0.10500 \mathrm{eV}$," Physical Review A, vol. 34, no. 5, pp. 3707-3722, 1986.

[82] F. A. Gianturco and S. Scialla, "Local approximations of exchange interaction in electron-molecule collisions: the methane molecule," Journal of Physics B, vol. 20, no. 13, pp. 3171-3189, 1987.

[83] F. A. Gianturco, A. Jain, and L. C. Pantano, "Electron-methane scattering via a parameter-free model interaction," Journal of Physics B, vol. 20, no. 3, pp. 571-586, 1987.

[84] P. McNaughten, D. G. Thompson, and A. Jain, "Low-energy electron- $\mathrm{CH}_{4}$ collisions using exact exchange plus parameterfree polarisation potential," Journal of Physics B, vol. 23, no. 13, p. 2405S, 1990.

[85] B. H. Lengsfield III, T. N. Rescigno, and C. W. McCurdy, "Ab initio study of low-energy electron-methane scattering," Physical Review A, vol. 44, no. 7, pp. 4296-4308, 1991.

[86] T. Nishimura and Y. Itikawa, "Elastic scattering of electrons by methane molecules," Journal of Physics B, vol. 27, no. 11, p. 2309, 1994.

[87] B. N. Nestmann, K. Pfingst, and S. D. Peyerimhoff, "R-matrix calculation for electron-methane scattering cross sections," Journal of Physics B, vol. 27, no. 11, p. 2297, 1994.

[88] F. A. Gianturco, J. A. Rodrigues-Ruiz, and N. Sanna, “The Ramsauer minimum of methane," Journal of Physics B, vol. 28, no. 7, p. 1287, 1995.

[89] M. H. F. Bettega, A. P. P. Natalense, M. A. P. Lima, and L. G. Ferreira, "Calculation of elastic scattering cross sections of lowenergy electrons by $\mathrm{PbH}_{4}$ and $\mathrm{SnH}_{4}$," The Journal of Chemical Physics, vol. 103, no. 24, pp. 10566-10570, 1995.

[90] I. Iga, M.-T. Lee, M. G. P. Homem, L. E. Machado, and L. M. Brescansin, "Elastic cross sections for e- $-\mathrm{CH}_{4}$ collisions at intermediate energies," Physical Review A, vol. 61, no. 2, Article ID 022708, 8 pages, 2000.

[91] M.-T. Lee, I. Iga, L. E. Machado, and L. M. Brescansin, "Model absorption potential for electron-molecule scattering in the intermediate-energy range," Physical Review A, vol. 62, no. 6, Article ID 062710, 7 pages, 2000.

[92] M. H. F. Bettega, M. T. N. Varella, and M. A. P. Lima, "Polarization effects in the elastic scattering of low-energy electrons by $\mathrm{XH}_{4}(\mathrm{X}=\mathrm{C}, \mathrm{Si}, \mathrm{Ge}, \mathrm{Sn}, \mathrm{Pb})$," Physical Review A, vol. 68, no. 1 , Article ID 012706, 7 pages, 2003. 
[93] E.-J. Ma, Y.-G. Ma, X.-Z. Cai, D.-Q. Fang, W.-Q. Shen, and W.D. Tian, "Differential cross sections of elastic electron scattering from $\mathrm{CH}_{4}, \mathrm{CF}_{4}$ and $\mathrm{SF}_{6}$ in the energy range $100-700 \mathrm{eV}$," Chinese Physics, vol. 16, no. 11, pp. 3339-3344, 2007.

[94] J. L. S. Lino, "Elastic electron scattering by $\mathrm{CH}_{4}$ in the lowenergy range," Physica Scripta, vol. 79, no. 2, Article ID 025303, 2009.

[95] A. Zecca, G. P. Karwasz, R. S. Brusa, and C. Szmytkowski, "Absolute total cross sections for electron scattering on $\mathrm{CH}_{4}$ molecules in the 1-4000 eV energy range," Journal of Physics B, vol. 24, no. 11, p. 2747, 1991.

[96] A. Zecca, G. P. Karwasz, and R. S. Brusa, “Total-cross-section measurements for electron scattering by $\mathrm{NH}_{3}, \mathrm{SiH}_{4}$, and $\mathrm{H}_{2} \mathrm{~S}$ in the intermediate-energy range," Physical Review A, vol. 45, no. 5, pp. 2777-2783, 1992.

[97] N. H. March, A. Zecca, and G. P. Karwasz, "Phenomenology and scaling of electron scattering cross sections from "almost spherical" molecules over a wide energy range," Zeitschrift für Physik D, vol. 32, no. 1, pp. 93-100, 1994.

[98] G. García and F. Manero, "Electron scattering by $\mathrm{CH}_{4}$ molecules at intermediate energies (400-5000 eV)," Physical Review A, vol. 57, no. 2, pp. 1069-1073, 1998.

[99] T. Sakae, S. Sumiyoshi, E. Murakami, Y. Matsumoto, K. Ishibashi, and A. Katase, "Scattering of electrons by $\mathrm{CH}_{4}, \mathrm{CF}_{4}$ and $\mathrm{SF}_{6}$ in the 75-700 eV range," Journal of Physics B, vol. 22, no. 9, pp. 1385-1394, 1989.

[100] S. S. Dhal, B. B. Srivastava, and R. Shingal, "Elastic scattering of electrons by methane molecules at intermediate energies," Journal of Physics B, vol. 12, no. 16, pp. 2727-2734, 1979.

[101] R. B. Brode, "The absorption coefficient for slow electrons in gases," Physical Review, vol. 25, no. 5, pp. 636-644, 1925.

[102] E. Briiche, "Wirkungsquerschnitt und Molekülbau," Annalen der Physik, vol. 83, no. 16, pp. 1065-1128, 1927.

[103] E. Briiche, "Wirkungsquerschnitt und Molekelbau in der Kohlenwasserstoffreihe: $\mathrm{CH}_{4}-\mathrm{C}_{2} \mathrm{H}_{6}-\mathrm{C}_{3} \mathrm{H}_{8}-\mathrm{C}_{4} \mathrm{H}_{10}$, Annalen der Physik, vol. 4, pp. 387-408, 1930.

[104] C. Ramsauer and R. Collath, "Über den Wirkungsquerschnitt der Nichtedelgasmoleküle gegenüber Elektronen unterhalb 1 Volt," Annalen der Physik, vol. 396, no. 1, pp. 91-108, 1930.

[105] E. Barbarito, M. Basta, M. Calicchio, and G. Tessari, "Low energy electron scattering from methane," The Journal of Chemical Physics, vol. 71, no. 1, pp. 54-59, 1979.

[106] H. Tanaka, T. Okada, L. Boesten, T. Suzuki, T. Yamamoto, and M. Kubo, "Differential cross sections for elastic scattering of electrons by $\mathrm{CH}_{4}$ in the energy range of 3 to $20 \mathrm{eV}$," Journal of Physics B, vol. 15, no. 18, pp. 3305-3319, 1982.

[107] J. Ferch, B. Granitza, and W. Raith, "The Ramsauer minimum of methane," Journal of Physics B, vol. 18, no. 13, pp. L445-L450, 1985.

[108] R. K. Jones, "Absolute total cross section for the scattering of low energy electrons by methane," The Journal of Chemical Physics, vol. 82, no. 12, pp. 5424-5427, 1985.

[109] B. Lohmann and S. J. Buckman, "Low-energy electron scattering from methane," Journal of Physics B, vol. 19, no. 16, pp. 25652570, 1986.

[110] W. Sohn, K.-H. Kochem, K.-M. Scheuerlein, K. Jung, and H. Ehrhardt, "Elastic electron scattering from $\mathrm{CH}_{4}$ for collision energies between 0.2 and 5 eV," Journal of Physics B, vol. 19, no. 21, pp. 3625-3632, 1986.

[111] L. Boesten and H. Tanaka, "Elastic DCS for e+ $\mathrm{CH}_{4}$ collisions, 1.5-100 eV,' Journal of Physics B, vol. 24, no. 4, p. 821, 1991.
[112] T. W. Shyn and T. E. Cravens, "Angular distribution of electrons elastically scattered from $\mathrm{CH}_{4}$," Journal of Physics B, vol. 23, no. 2, p. 293, 1990.

[113] N. Oda, "Energy and angular distributions of electrons from atoms and molecules by electron impact," Radiation Research, vol. 64, no. 1, pp. 80-95, 1975.

[114] Z. N. Ozer, H. Chaluvadi, M. Ulu, M. Dogan, B. Aktaş, and D. Madison, "Young's double-slit interference for quantum particles," Physics Review A, vol. 87, no. 4, Article ID 042704, 8 pages, 2013.

[115] M. Ulu, Z. N. Ozer, M. Yavuz et al., "Experimental and theoretical investigation of $(e, 2 e)$ ionization of $\operatorname{Ar}(3 p)$ in asymmetric kinematics at $200 \mathrm{eV}$,' Journal of Physics B, vol. 46, no. 11, Article ID 115204, 2013.

[116] M. Dogan, M. Ulu, and O. Sise, "Design, simulation and construction of an electron-electron coincidence spectrometer," Journal of Electron Spectroscopy and Related Phenomena, vol. 161, no. 1-3, pp. 58-62, 2007.

[117] M. Ulu, O. Sise, and M. Dogan, "Optimizing the performance of an electron gun design followed by lenses and apertures," Radiation Physics and Chemistry, vol. 76, no. 3, pp. 636-641, 2007.

[118] M. Dogan, O. Sise, and M. Ulu, "Design of electron energy analyzers for electron impact studies," Radiation Physics and Chemistry, vol. 76, no. 3, pp. 445-449, 2007.

[119] M. Dogan, A. Crowe, K. Bartschat, and P. J. Marchalant, "Simultaneous excitátion-ionization of helium to the $\mathrm{He}+(2 \mathrm{p})$ state," Journal of Physics B, vol. 31, no. 7, pp. 1611-1624, 1998.

[120] M. Dogan and A. Crowe, "Correlation studies of excited states of the helium ion," Journal of Physics B, vol. 33, no. 12, pp. L461L465, 2000.

[121] M. Dogan and A. Crowe, "Coincidence studies of the influence of resonances on simultaneous ionization-excitation of helium by electron impact," Journal of Physics B, vol. 35, no. 12, pp. 27732781, 2002.

[122] M. Dogan, "Investigation of excitation-ionization using double coincidence measurements," Russian Journal of Physical Chemistry A, vol. 76, no. 1, pp. S104-S108, 2002.

[123] O. Sise, M. Dogan, I. Okur, and A. Crowe, "(e, 2e) experiments on $\left(2 s^{2}\right)^{1} S,\left(2 p^{2}\right)^{1} D$ and $(2 s 2 p)^{1}$ autoionizing levels of helium in the direction of the binary lobe," Journal of Physics B, vol. 43, no. 18, Article ID 185201, 2010.

[124] O. Sise, M. Dogan, I. Okur, and A. Crowe, "Electron-impact excitation of the $\left(2 \mathrm{p}^{2}\right)^{1} \mathrm{D}$ and $(2 \mathrm{~s} 2 \mathrm{p}){ }^{1} \mathrm{P}^{o}$ autoionizing states of helium," Physical Review A, vol. 84, no. 2, Article ID 022705, 13 pages, 2011.

[125] Z. N. Ozer, F. Olgaç, M. Ulu, and M. Dogan, "Double differential cross-section measurements for electron impact ionization of Helium," Acta Physica Polonica A, vol. 123, no. 2, p. 361, 2013.

[126] O. Sise, M. Ulu, and M. Dogan, "Characterization and modeling of multi-element electrostatic lens systems," Radiation Physics and Chemistry, vol. 76, no. 3, pp. 593-598, 2007.

[127] O. Sise, M. Ulu, and M. Dogan, "Aberration coefficients of multi-element cylindrical electrostatic lens systems for charged particle beam applications," Nuclear Instruments and Methods in Physics Research A, vol. 573, no. 3, pp. 329-339, 2007. 

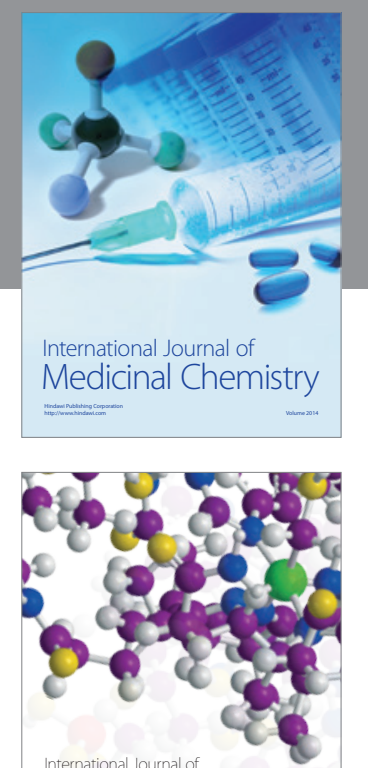

\section{Carbohydrate} Chemistry

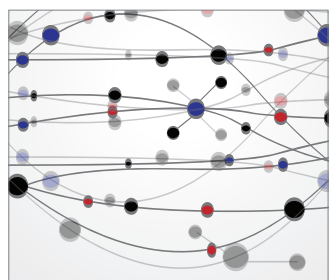

The Scientific World Journal
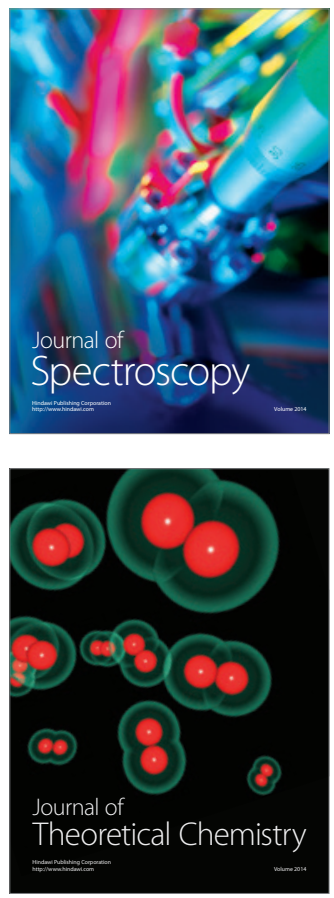
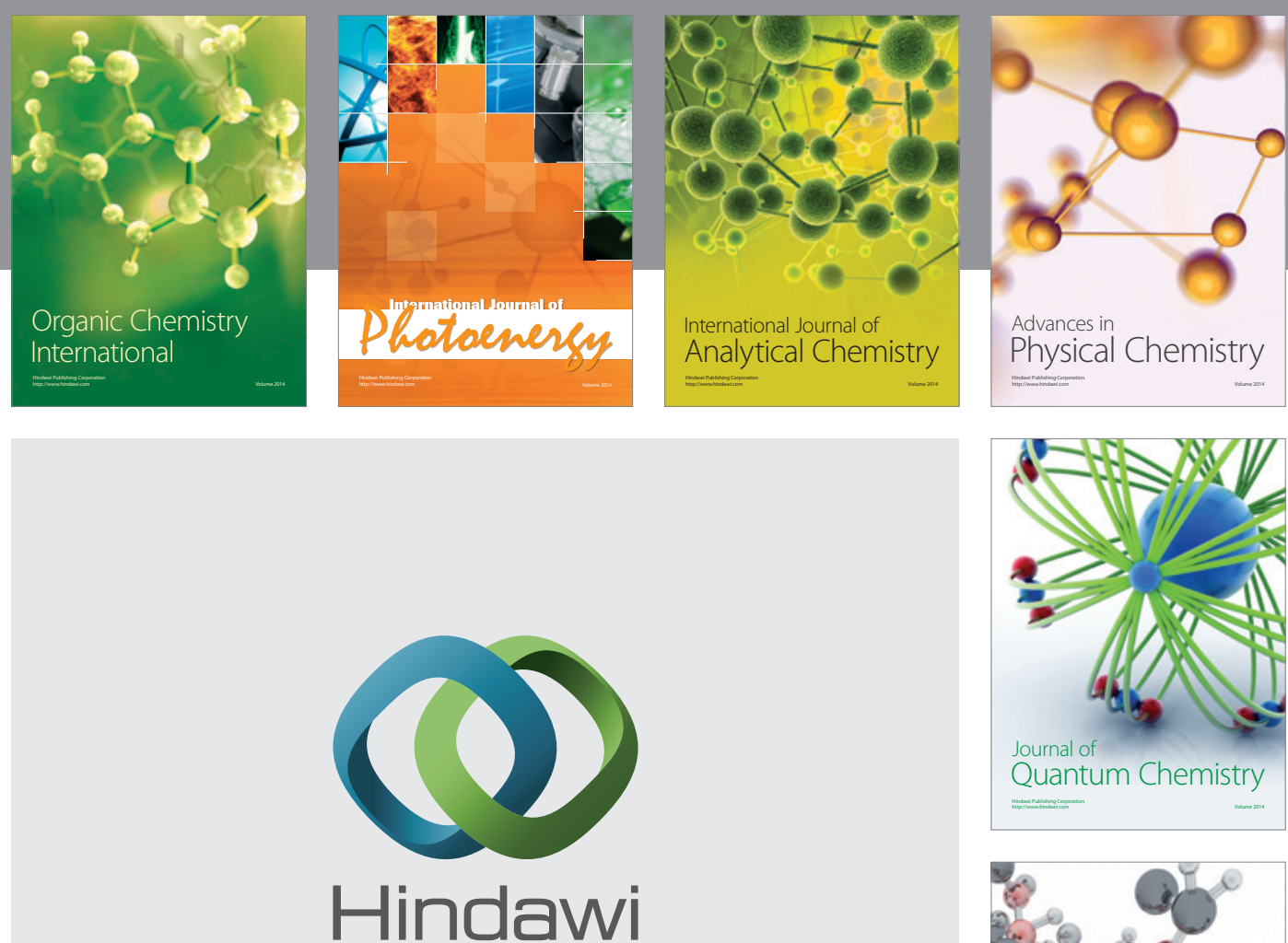

Submit your manuscripts at

http://www.hindawi.com

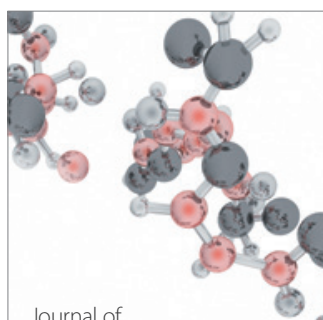

Analytical Methods

in Chemistry

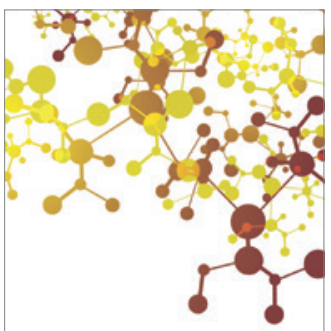

Journal of

Applied Chemistry

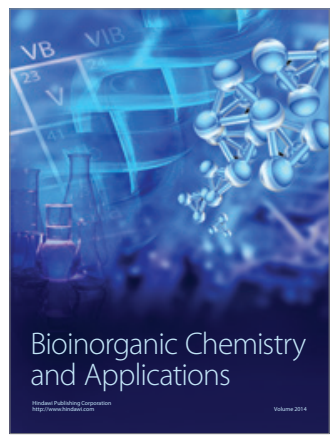

Inorganic Chemistry
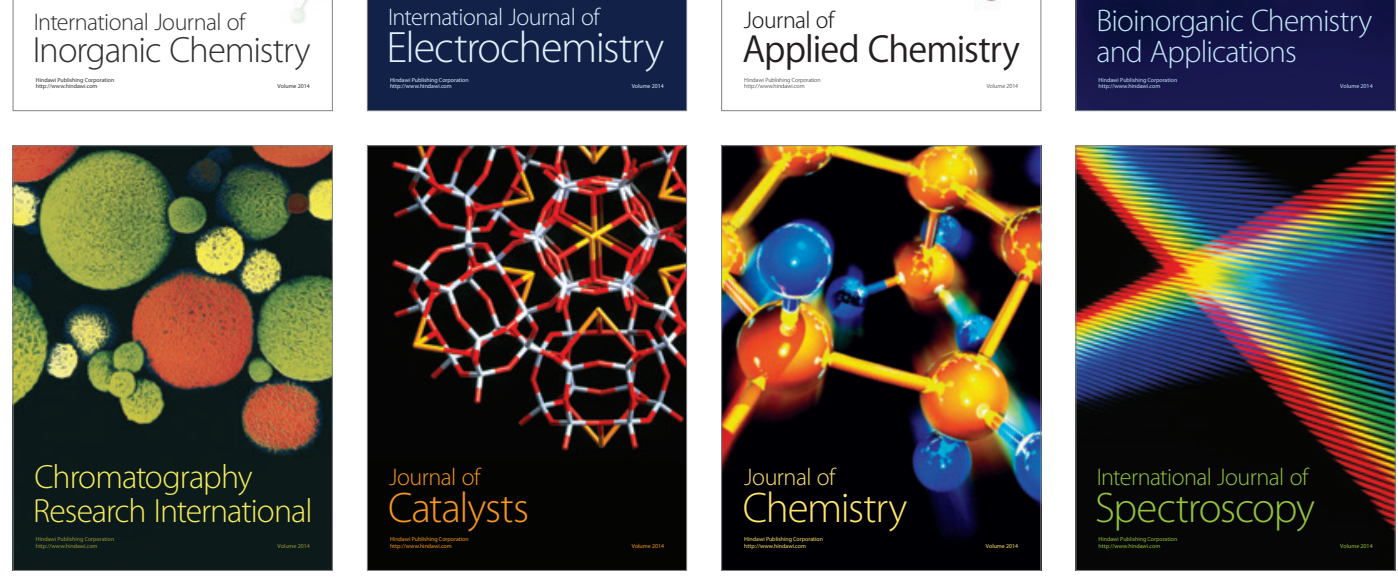